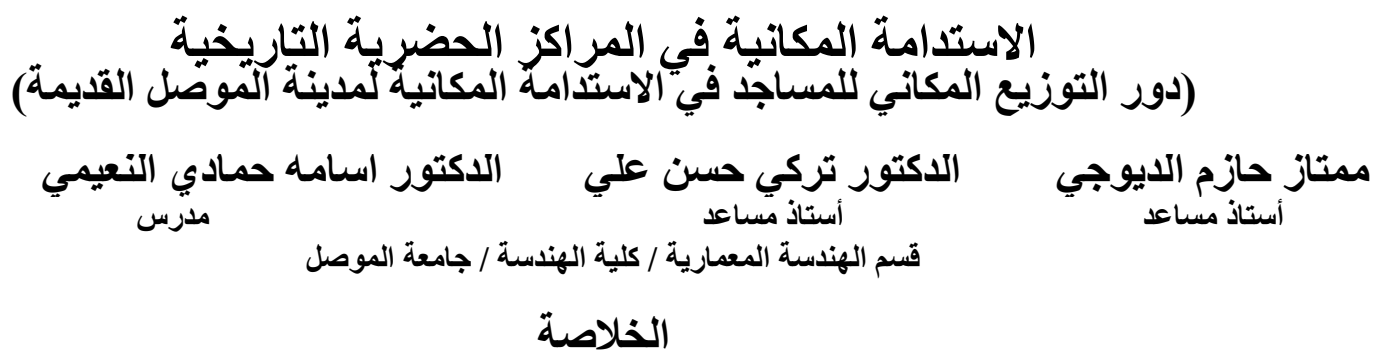

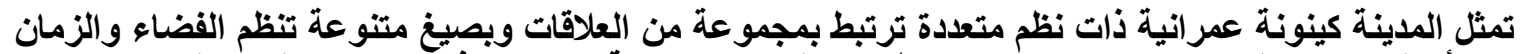

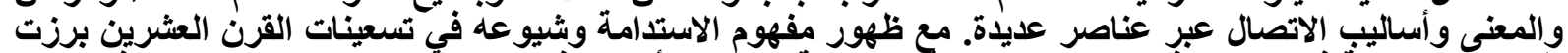

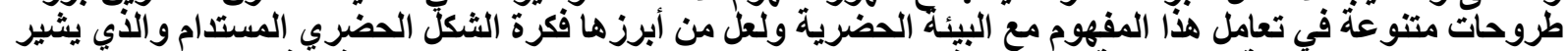

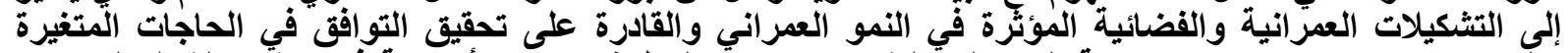

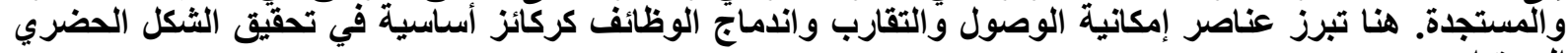

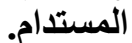

في المدينة الإسلامية ظهر المسجد كعنصر أساسي تتمحور حوله الفعاليات العضرية، فلم يكن الجامع مركزا دينيا

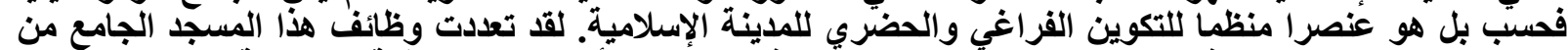

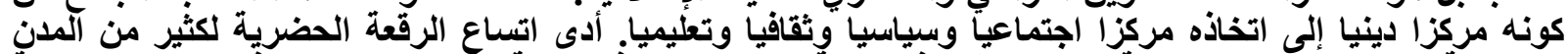

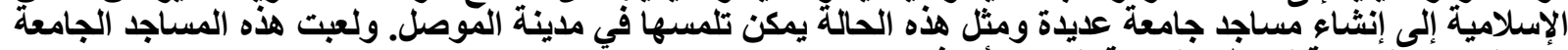

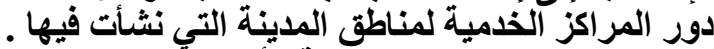

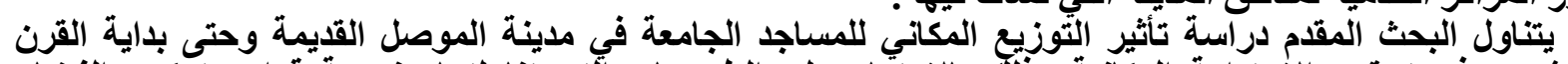

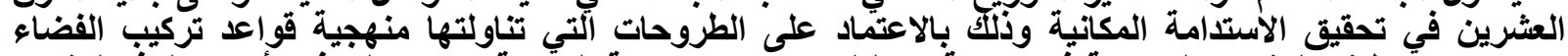

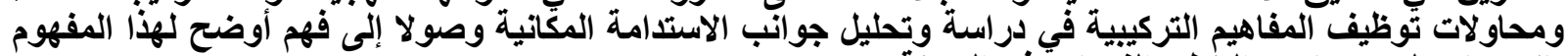

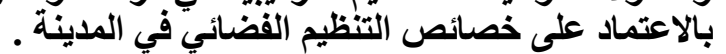

\title{
Spatial Sustainability in Historical Urban Centers The role of Spatial Distribution of Mosques in the Spatial Sustainability in Mosul Old City
}

\author{
M.H.Aldewaje Dr. T.H.Ali Dr. O.H.Al-Nuaemi \\ Architecture Department / university of Mosul
}

\begin{abstract}
:
The city represents a multi-systems physical entity associated with a range of relationships in various aspects, which organize space, time, meaning and means of communication through many elements. With the vast expanded rising of the concept of sustainability since the last decade of the $20^{\text {th }}$. Centaury, many trends are adopted in dealing with this concept within the urban environment. The idea of sustainable urban form, which refers to spatial and physical configuration which affects urban growth and capable of achieving compatibility with the changing and emerging needs, is the most dominant one. The elements of accessibility, proximity and functional mix are the basic means of achieving sustainable urban form.
\end{abstract}

In Islamic city, the mosque was a key element, which urban facilities were gathered around it, it was not just a religious center, but it was an organizer of the spatial configuration of the Islamic city. The multiple functions of the mosque vary from a religious center to a social, political, cultural and educational center. For many Islamic cities, the urban growth has led to establishment of many mosques, where the city of Mosul is a good example for such case. These mosques played the role of multi-purpose centers in the districts they found.

The presented research tries to investigate the role of the spatial distribution of the Friday mosques in Mosul old city until the beginning of the 20th. Centaury in spatial sustainability. This will be done by adopting space- syntax approach and the concept of spatial sustainability focused on the spatial configuration of the city.

Keywords: Friday Mosque, Spatial Sustainability, Sustainable Urban Form, Islamic City, Mosul.

$$
\text { قبل: } 2012 \text { - } 9 \text { - } 19
$$

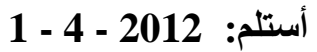




\section{1}

: 1 - 1 - توطئة:

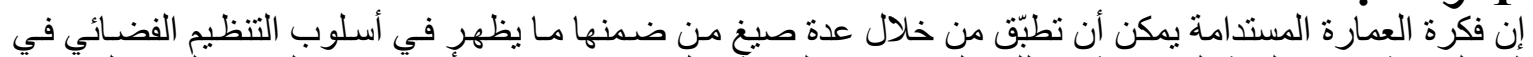

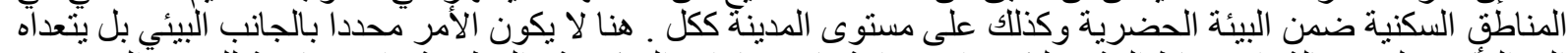

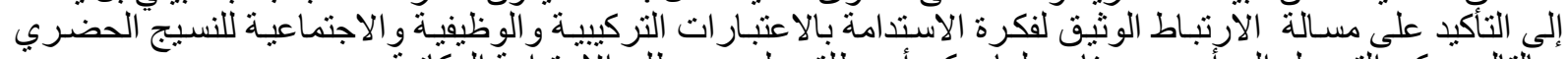

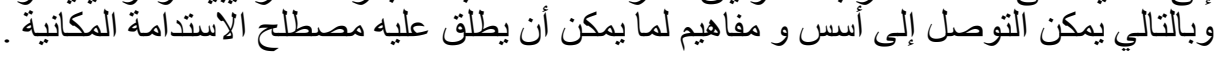

: 1

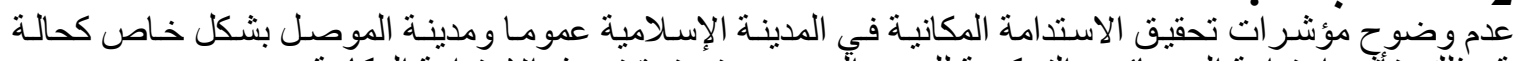

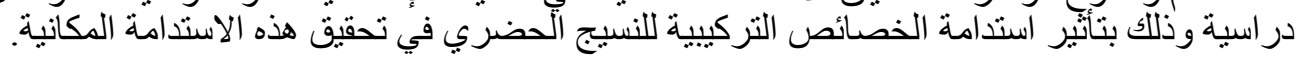

ا 1

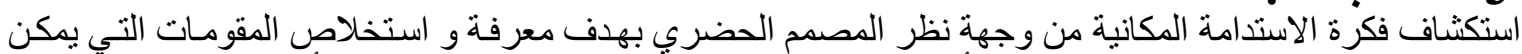

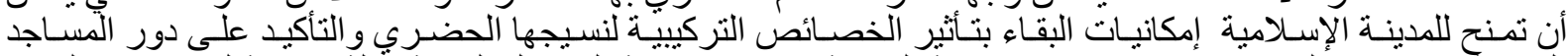

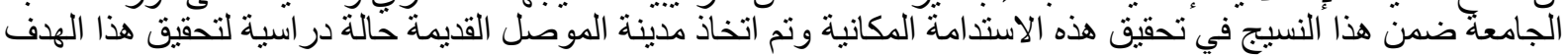

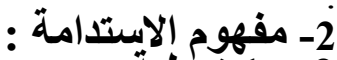
: 1 - 1 - مفوم: مفئة

طرح مفهوم الاستدامة Sustainability نفسـه للتداول خـلال النصف الثناني من القرن العشرين و حيث عرفت

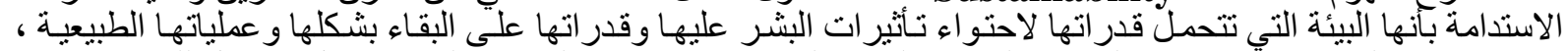

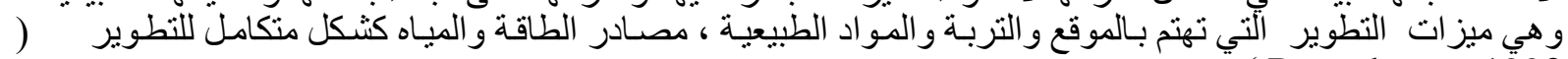
. Rosenbaum, 1993

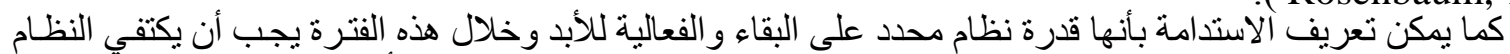

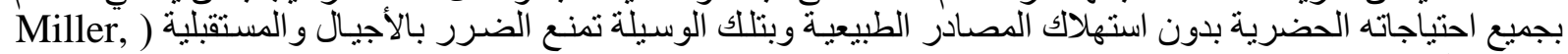

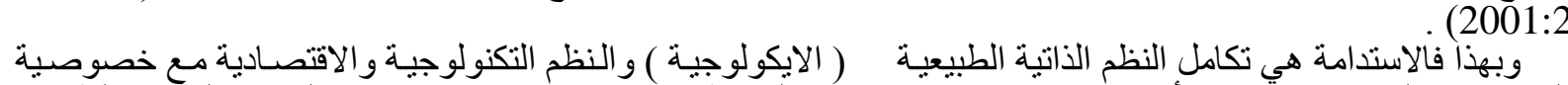

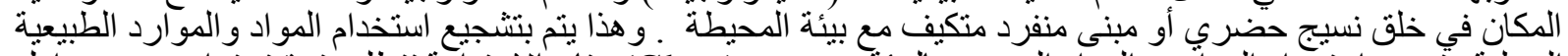

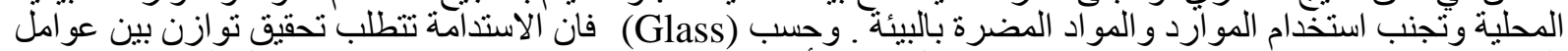

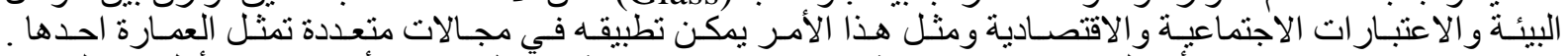
(Glass,2003:296)

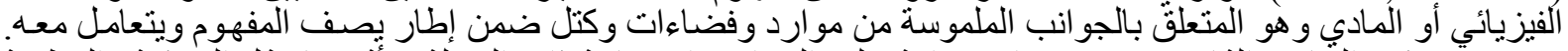

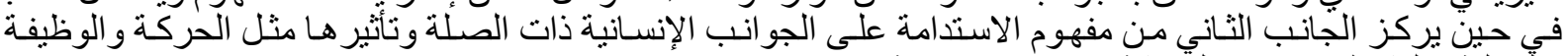

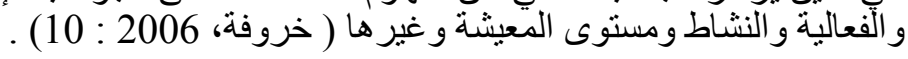

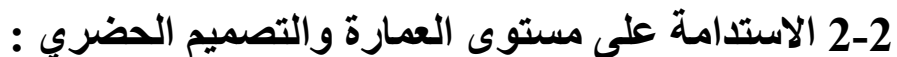

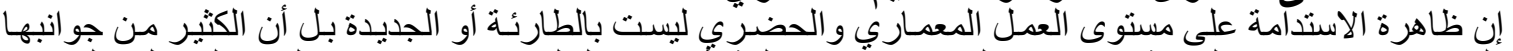

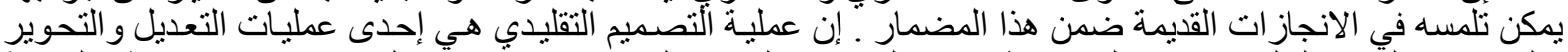

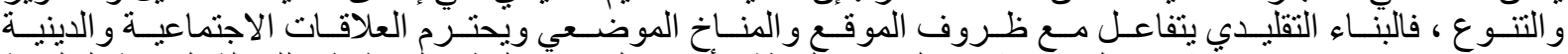
(Rapaport,1969:4)

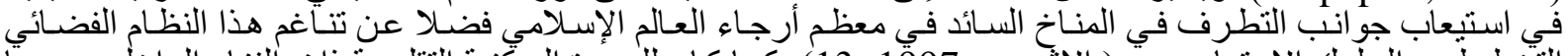

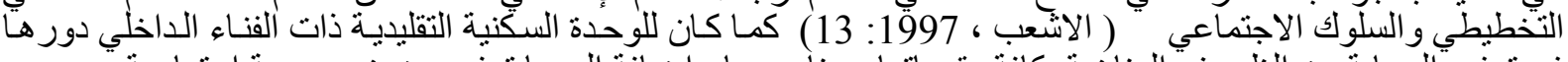

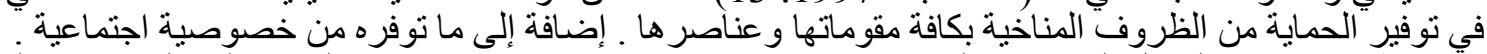

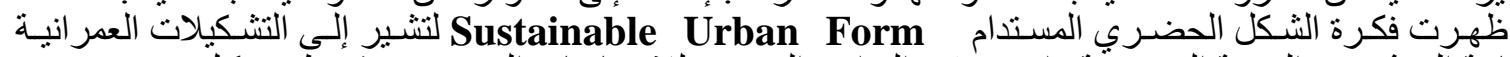

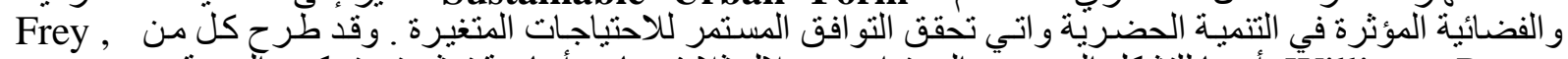

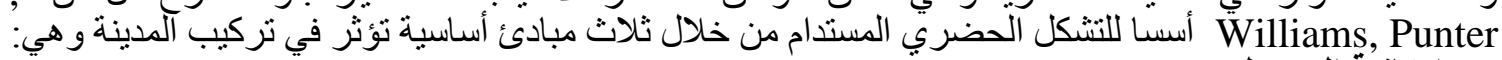
1 - إمكانية الوصول Accessibility

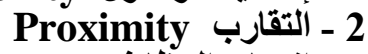

3 - اندماج الوظائف

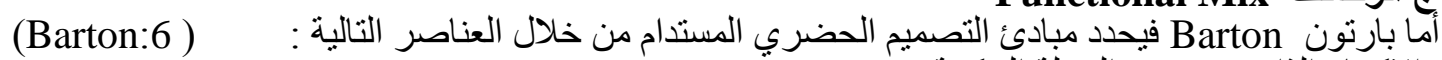

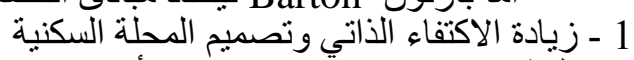

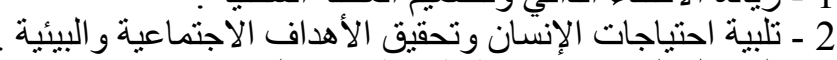

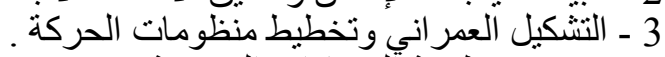

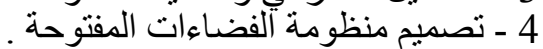

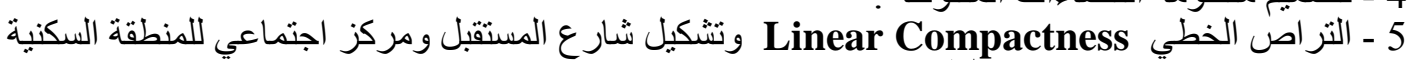
6 - إستر اتيجية استخدام وترشيد الطاقة . 7 - أستر اتيجية استخدام وترشيد المياه . 


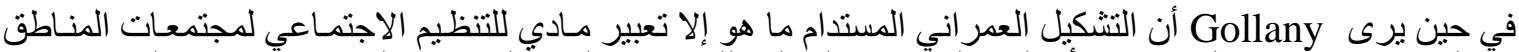

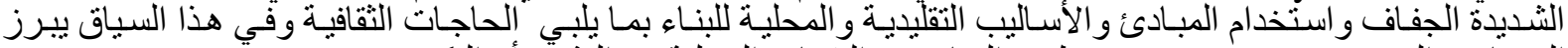
المعماري المصري حسن فتحي في توظيف العناصر و التقنيات المحلية في التشييد أو التكييف .

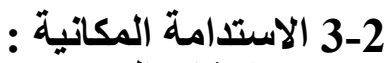

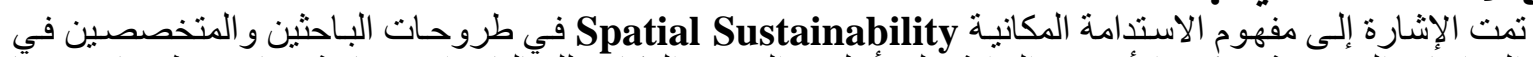

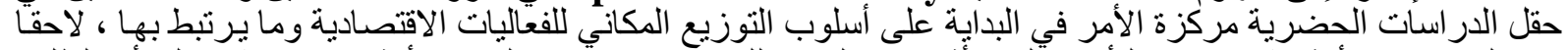

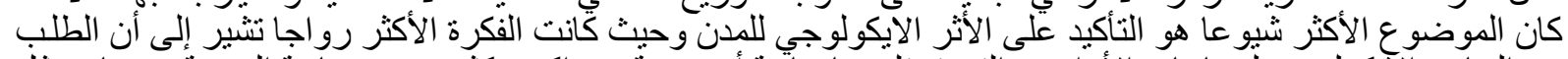

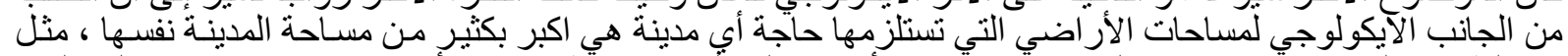

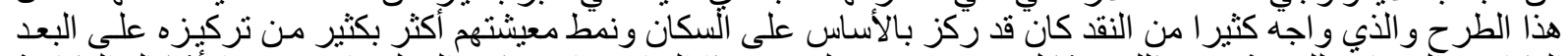

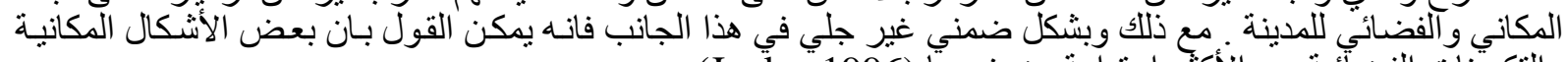

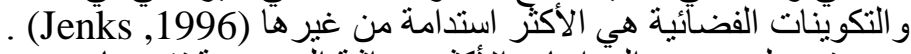

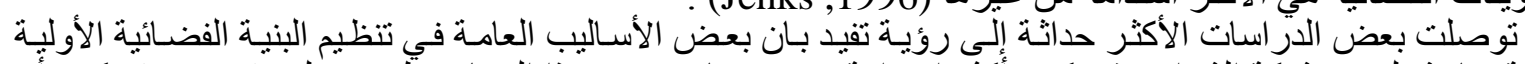

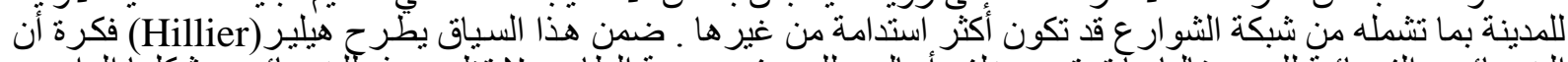

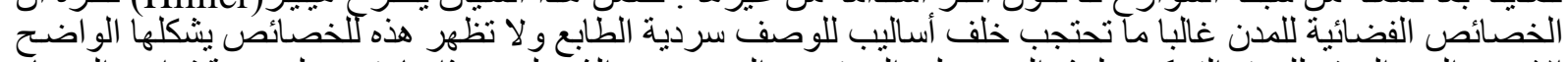

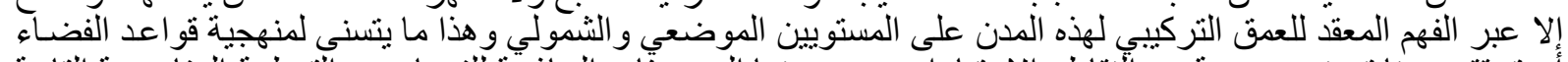

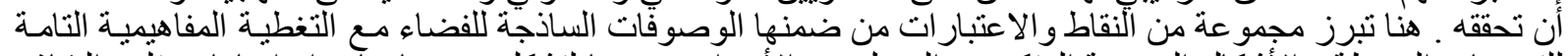

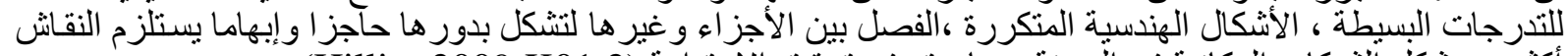

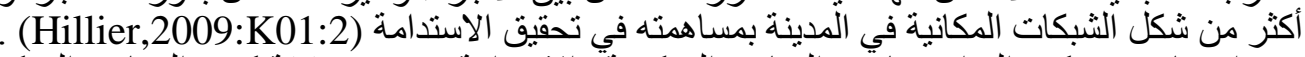

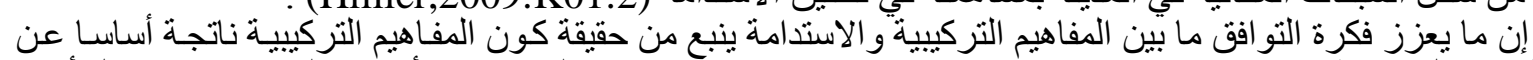

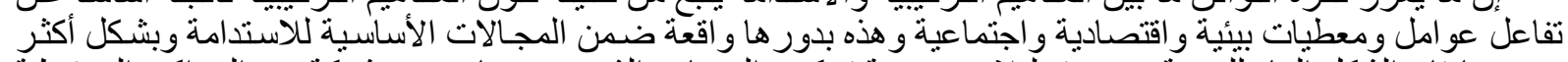

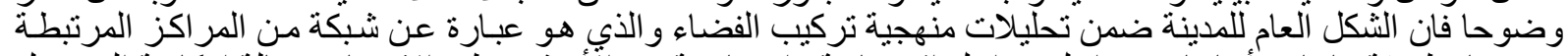

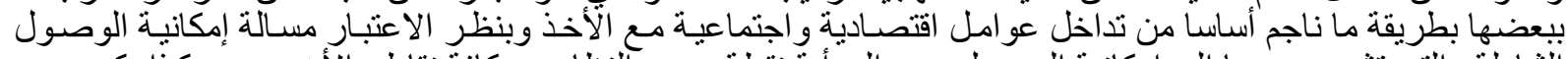

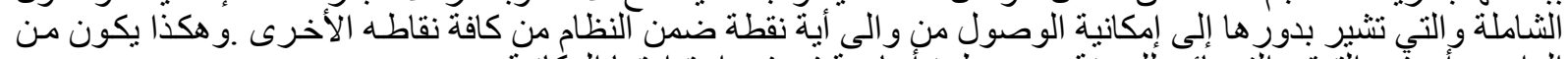

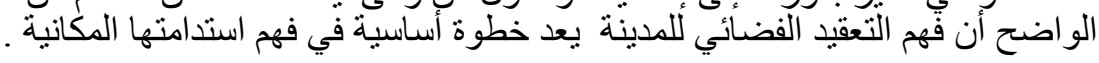

\section{3 - 1 ـ الجوامجة في المدينة الإسلامية :}

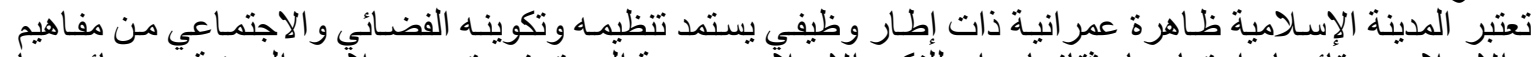

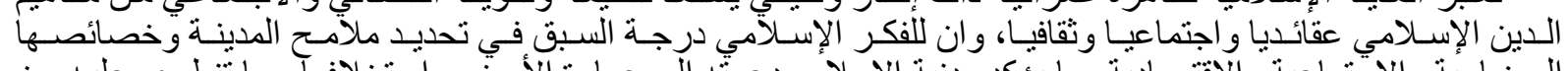

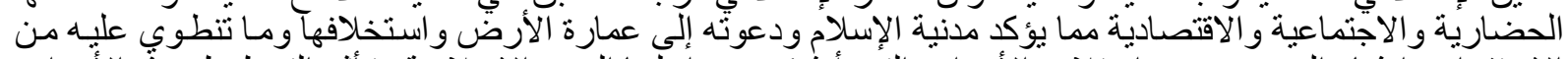

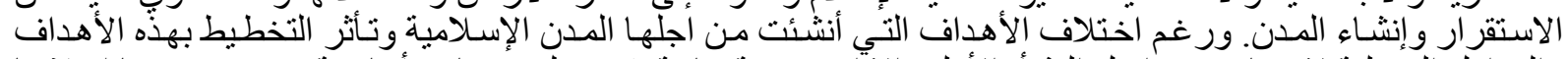

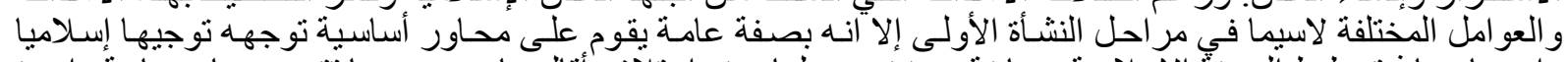

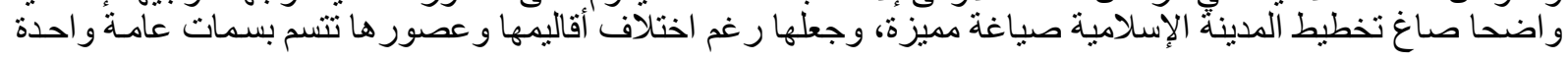

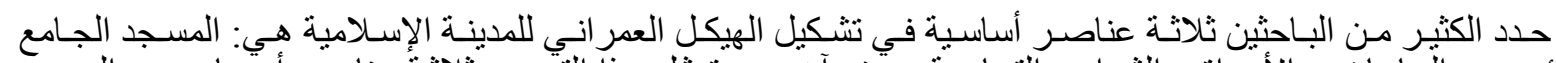

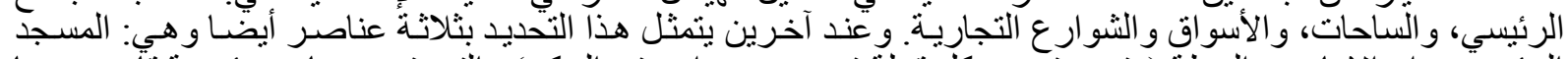

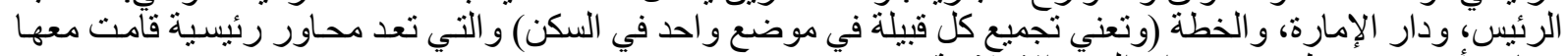

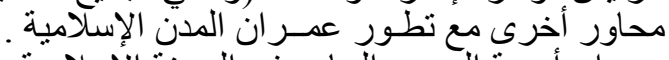

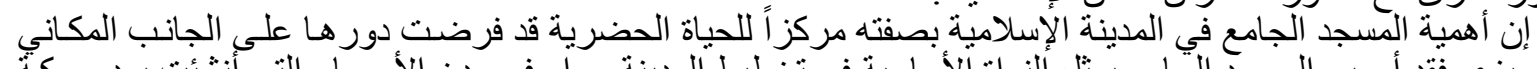

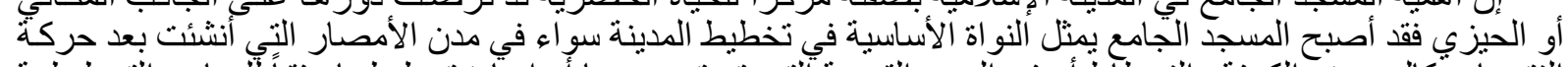

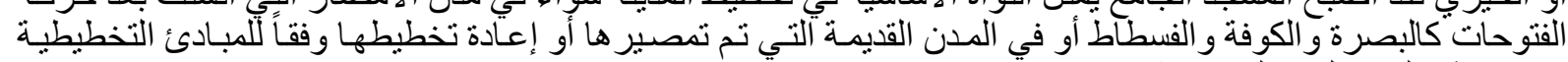
الإسلامية كالموصل وحلب ودمشق .

3 - 2 تطور الجوامع في المدينة الإسلامية :

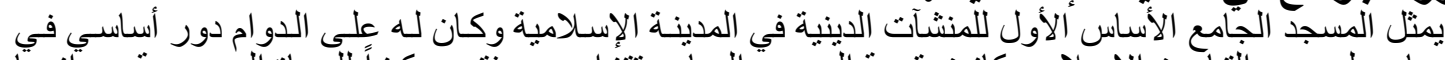

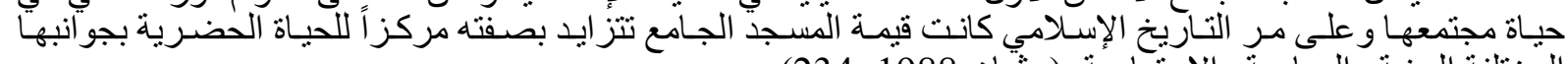

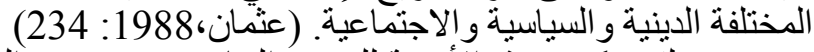

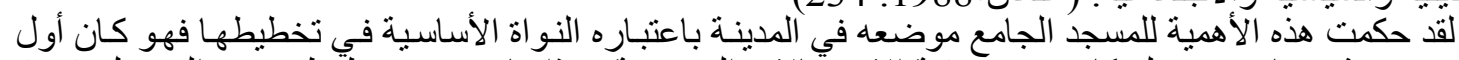

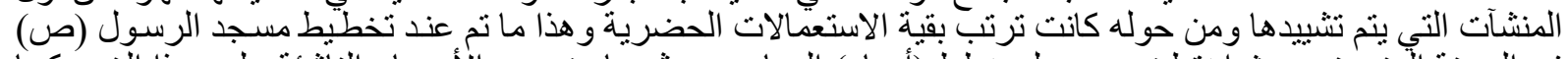

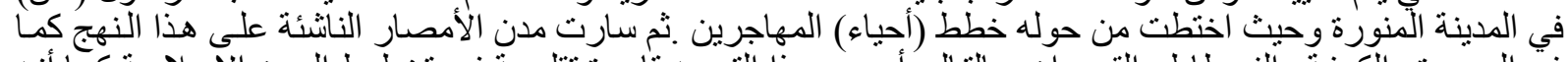

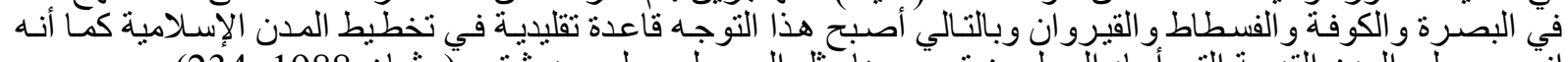

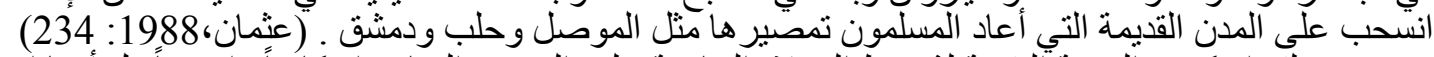

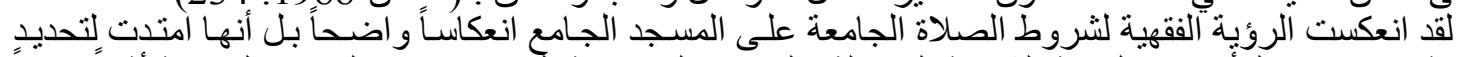

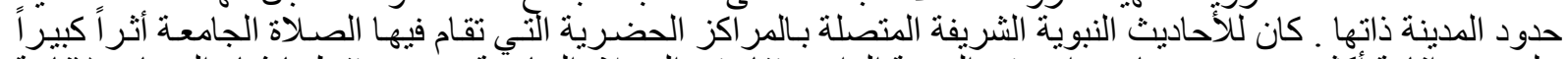

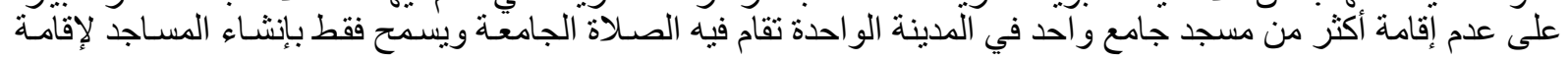


الصلو ات الخمسـة في خطط (أحياء) المدينـة وهذه المسـاجد قد أطلق عليها ) مسـاجد الخمسـة) تمييز اً لهـا عن المسـد

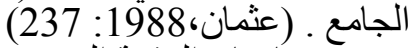

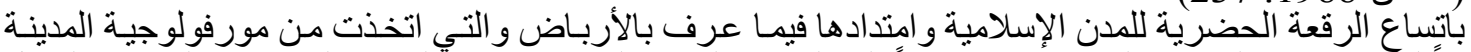

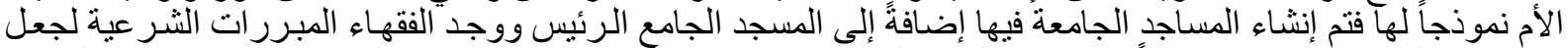

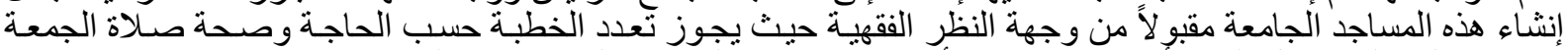

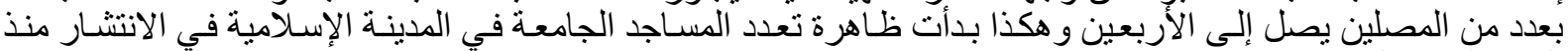
القرن السابع الهجري المبن ــ (عثمان،1988: 238)

: 3 - 3 الدر اسات السابقة الابة

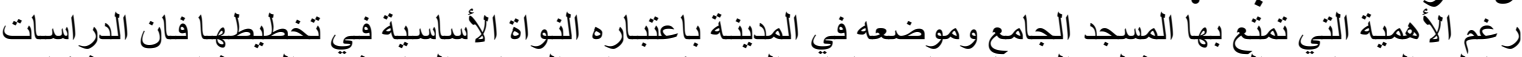

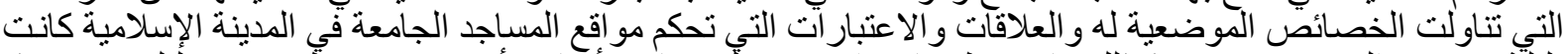

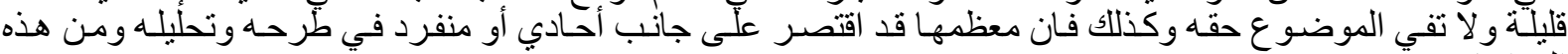

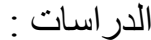

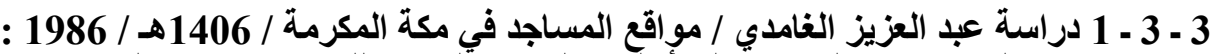

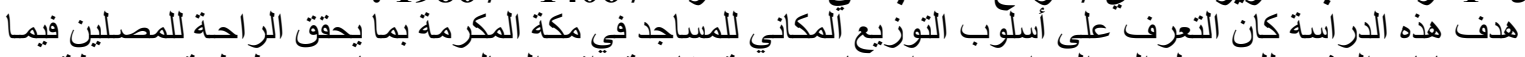

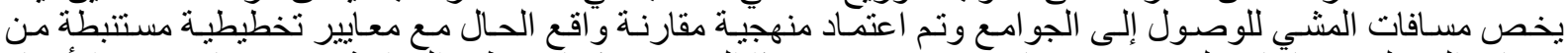

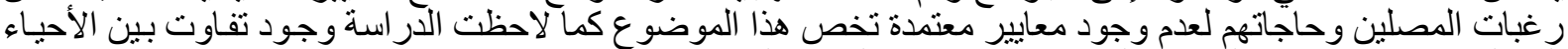
المختلفة فيما يخص عدد الجو امع القائمة ونصف قطر الخدمة الذي تغطيه .

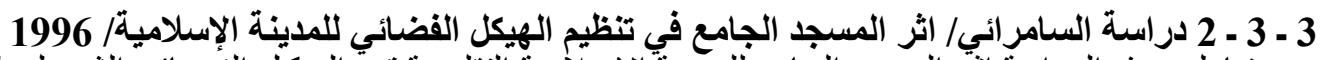

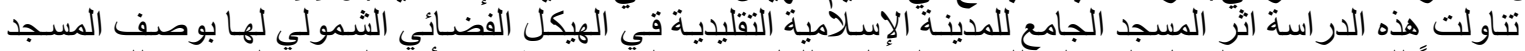

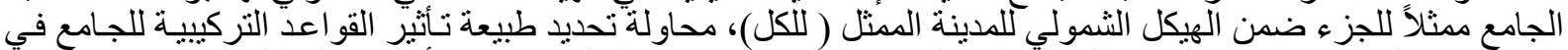

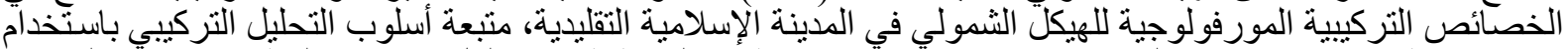

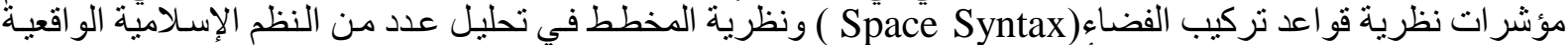

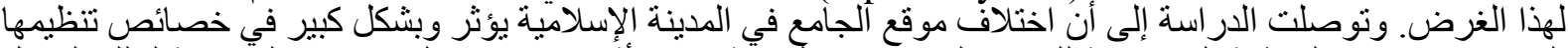

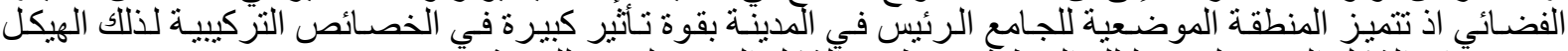

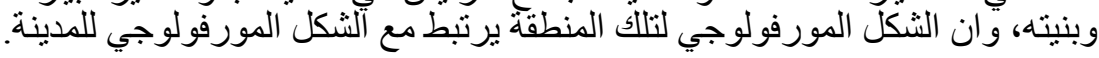

3 - 3 - 3 دراسـة فارس مطلوب / العلاقـة بين خصـائص التنظيم الفضـائي وتوقيع الفعاليـات الحضـرية في المدينـة

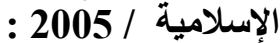

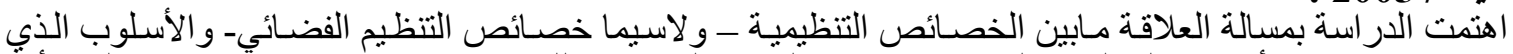

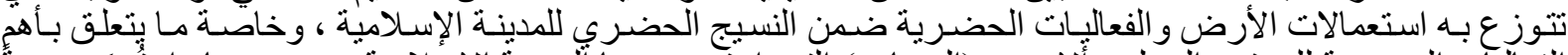

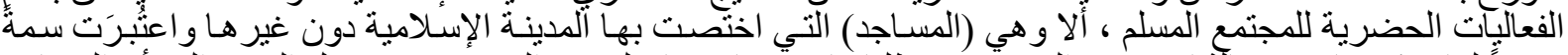

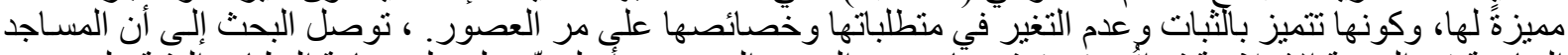

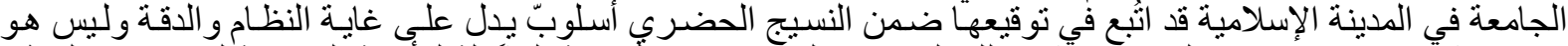

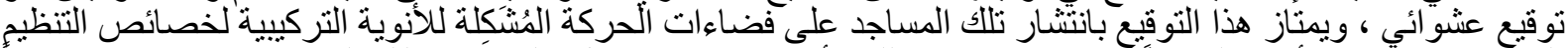

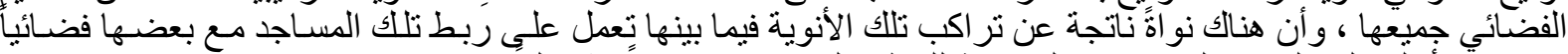

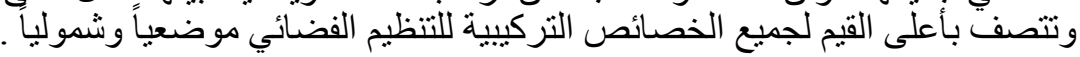

3 - 3 - 4 دراسة ممتاز الديوجي / خصائص التوزيع المكاني للجوامع في المدينة الإسلامية / 2007 :

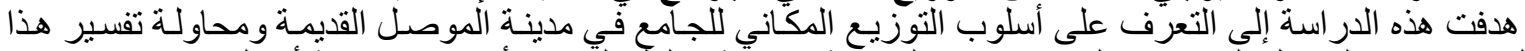

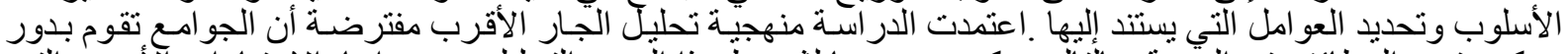

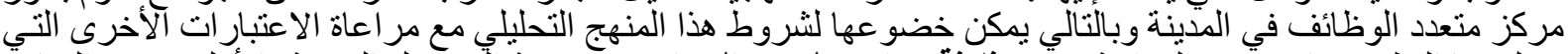

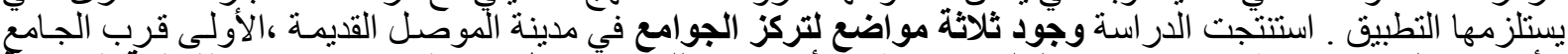

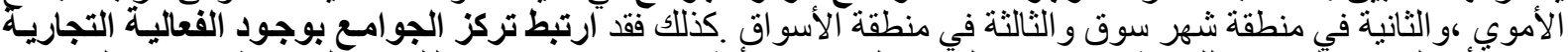

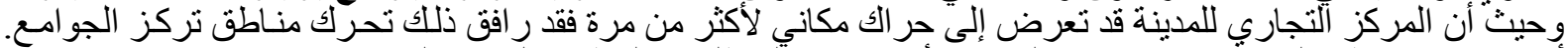

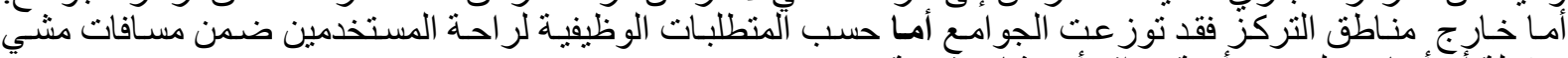

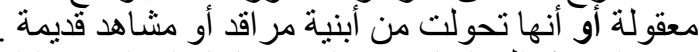

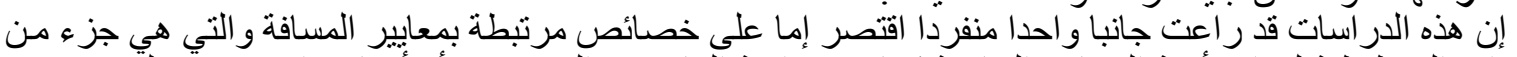

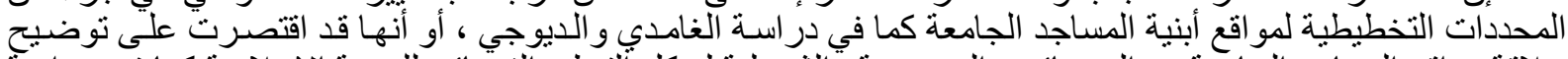

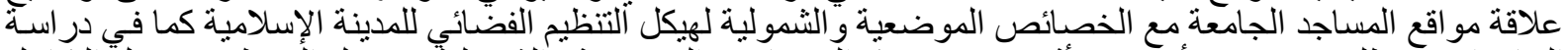

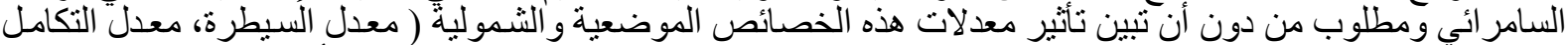

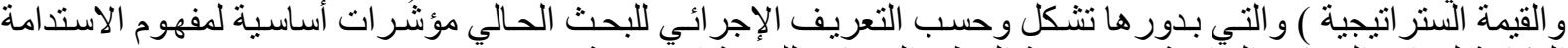
المكانية لمو اقع المساجد الجامعة ضمن بنية التنظيم الفضائي للمدينة الاسلامية. 


\section{4 - 4 فرضية البحث :}

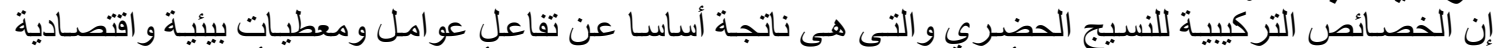

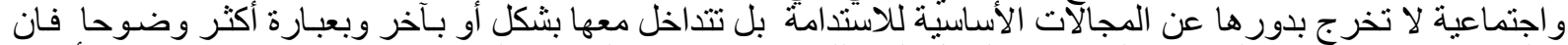

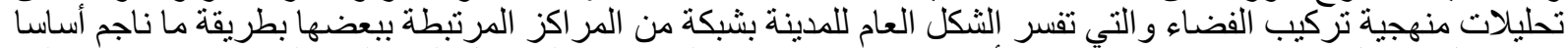

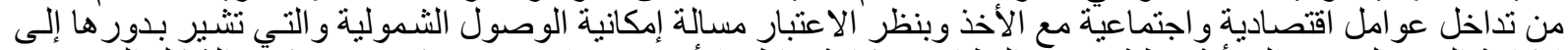

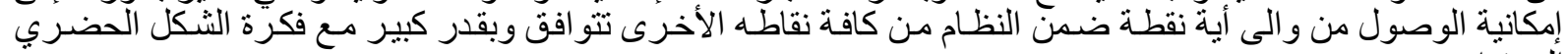

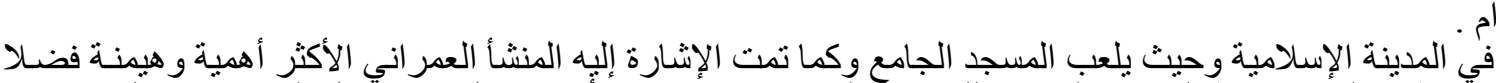

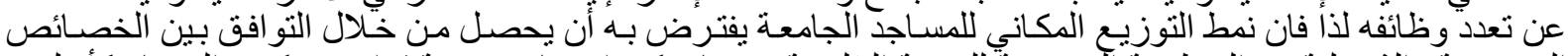

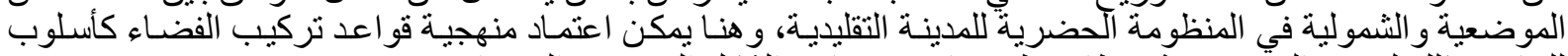

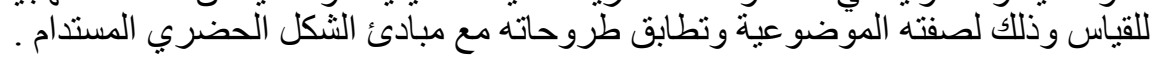

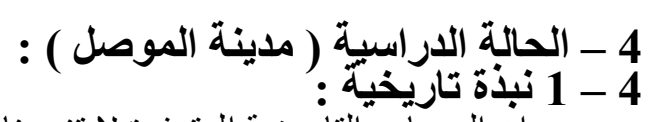

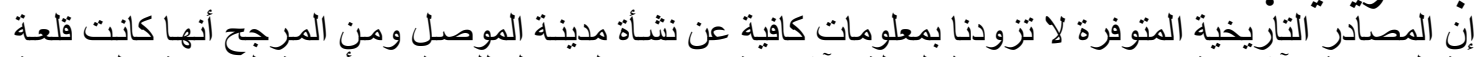

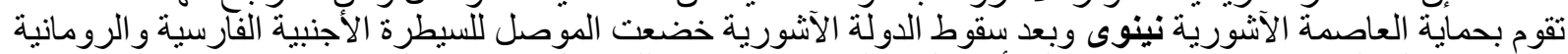

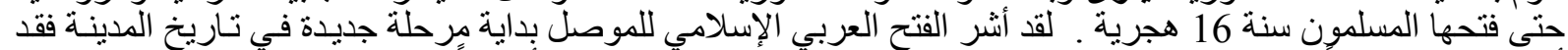

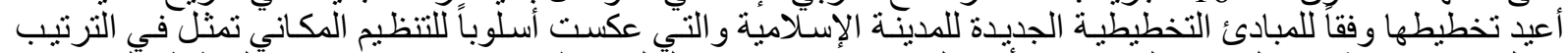

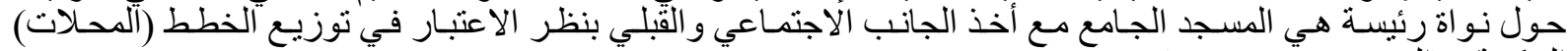

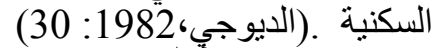

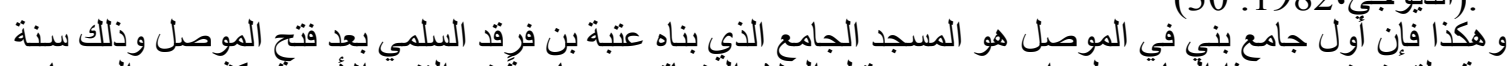

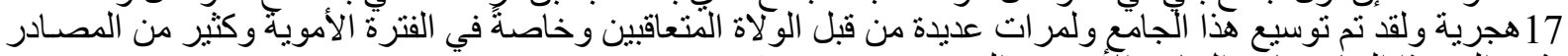

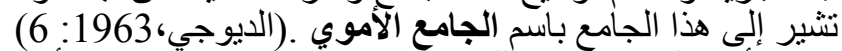

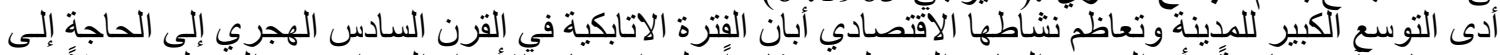

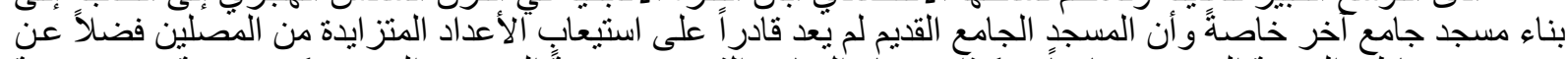

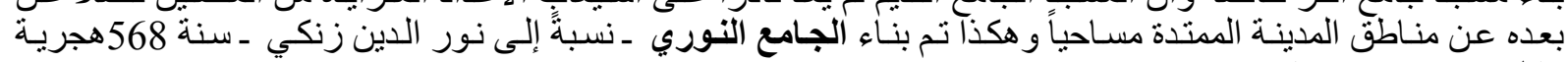
(ناجي، داجن 1986:

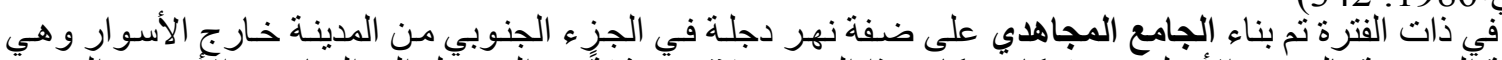

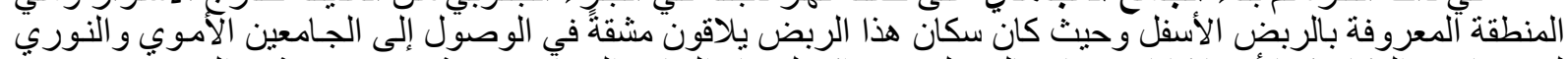

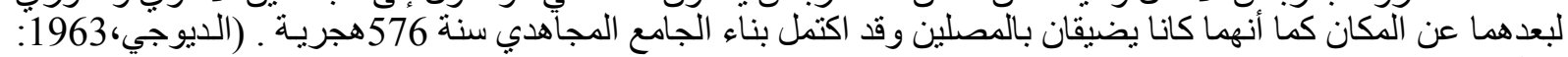

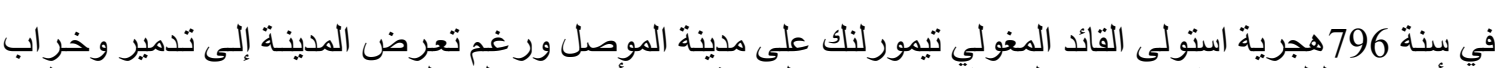

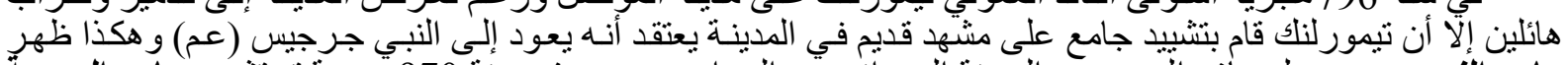

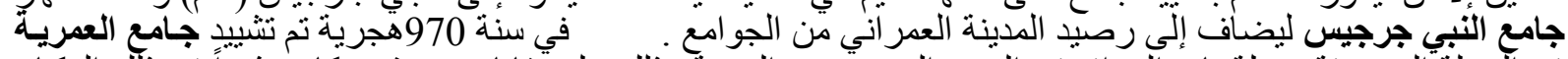

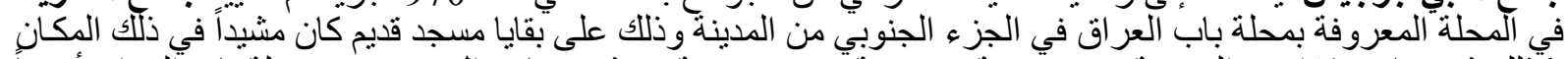

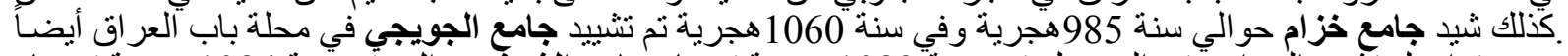

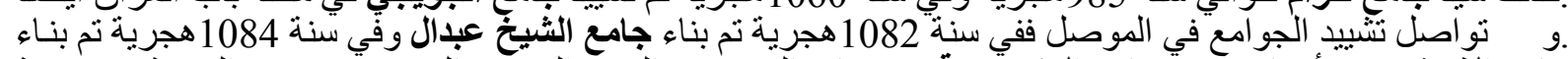

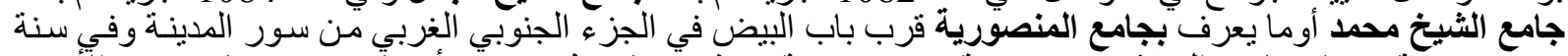

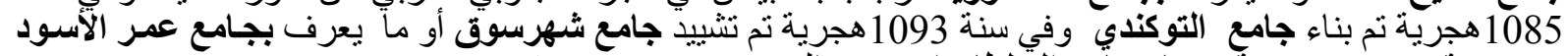

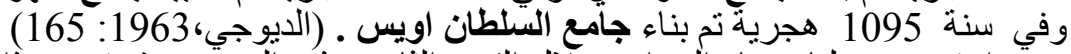

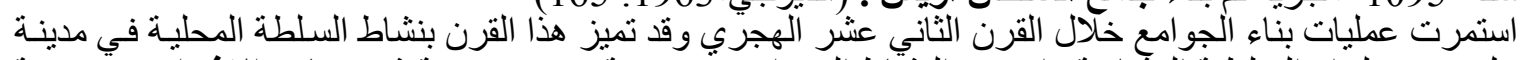

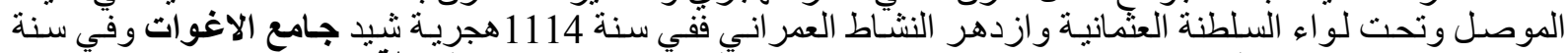

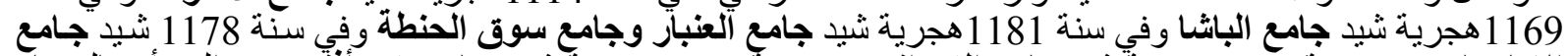

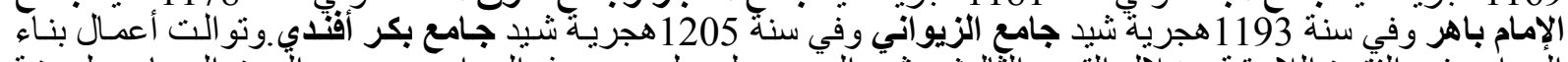

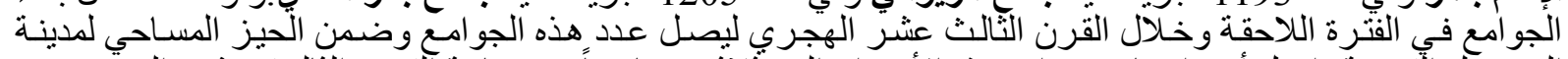

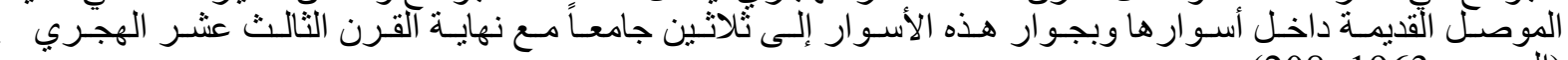

(الديوجي، 1963: 208)

4

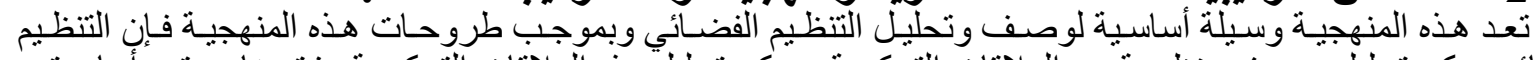

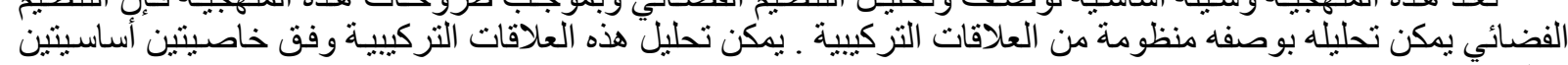
(Hillier, 1984:97-153): Lo

1 ـ خاصية التناظر ـ اللا تناظر :

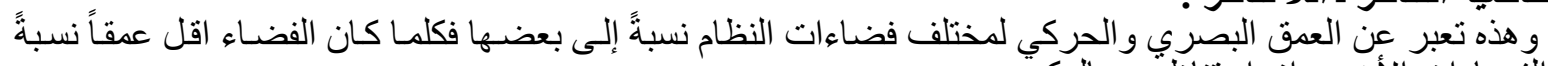

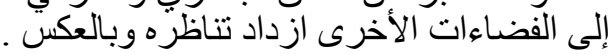




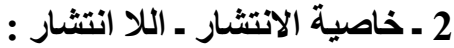

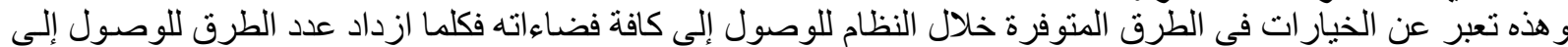

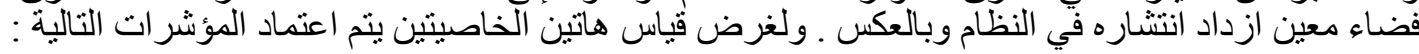

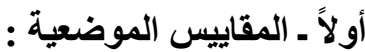

و هذه تحدد طبيعة علاقة الفضاء مع الفضاءات المجاورة له بشكل مباشر وتشمل :

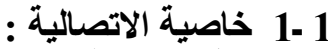

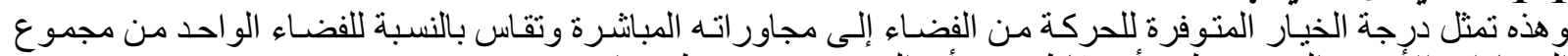

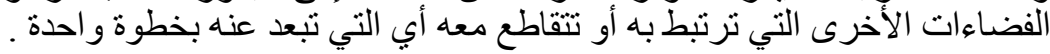

2 1 -2 خاصية السيطرة الموضعية : و هذه تمثل درجة الخيار التي يوفرهاء ها الفضاء للحركة إليه من الفضاءات المجاورة له بشكل مباثر وتقاس من مجموع

$E_{V}=\Sigma 1 / n$

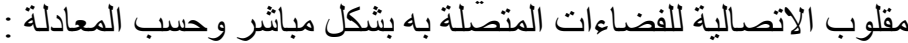

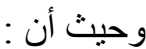

E

n : اتصالية الفضاءات المنصلة بذلك الفضاء .اي الارتباطات المحورية لكل خط محوري يرتبط بالفضاء بشكل مباثر.

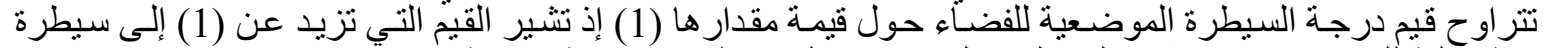

موضعية عالية للفضاء في حين تشير القيم التي تقل عن (1) إلى سبطرة موضعية ضعيفة .

1 -3 معدل درجة السيطرة الموضعية للفضاعات التي هي بتماس مع المسجد الجامع.

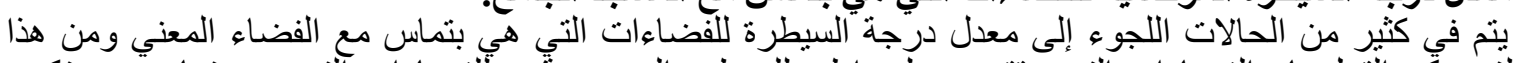

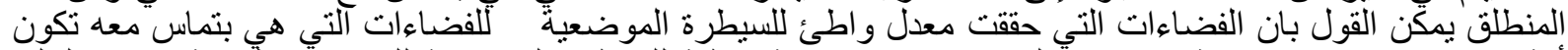

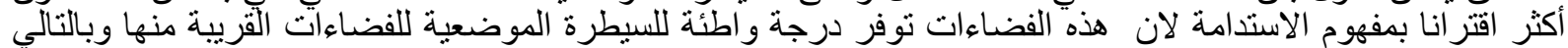

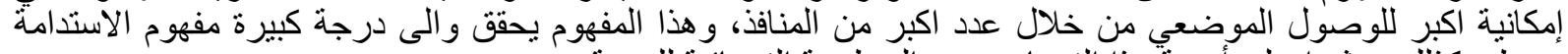

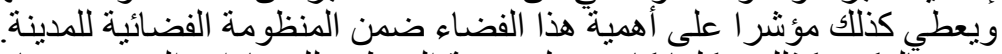

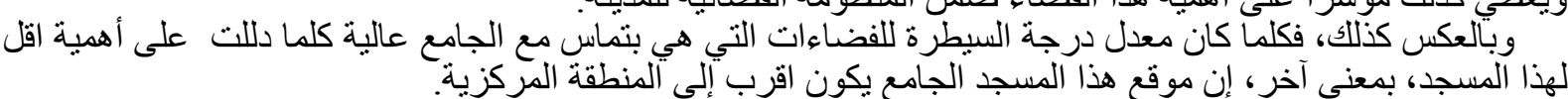

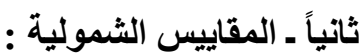

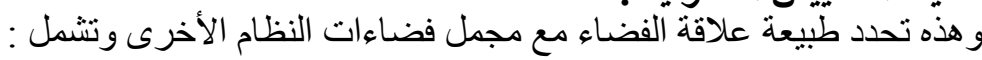

$\mathrm{MD}=\Sigma \mathrm{D} /(\mathrm{K}-\mathbf{1})$

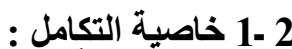
و هذه تمثل مقياساً لمدى عدم التناظر النسبي ضمن النظام الفضائي ويتم حساب درجة تكامل الفضاء كما يلي ا ـ حساب معدل عمق الفضاء

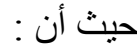
MD ع : : D

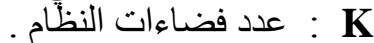

$\mathbf{R A}=2(\mathrm{MD}-1) /(\mathrm{K}-2)$ ب - مساب عدم التناظر النسبي RA من المعادلة :

$$
\begin{aligned}
& \text { حيث أن : } \\
& \text { : : : درجة عدم التناظر النسبي للفضاء . : } \\
& \text { : معدل العمق للفضاء : MD }
\end{aligned}
$$

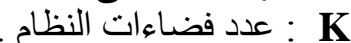

تتحصر قيم RA بين ( صفر - 1 1) حيث تعبر القيمة (1) عن عدم تناظر نسبي مرتفع مما يشير إلى فضاء معزول بشكل

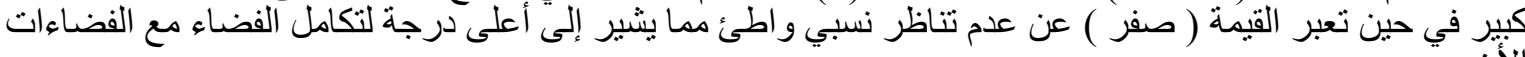

$\mathbf{R R A}=\mathbf{R A} / \mathbf{D}_{\mathbf{K}}$ ج - مساب عدم التناظر النسبي المعدل RRA من المعادلة : 
تتر اوح قيم RRA حول قيمة مقدارها (1) وهي القيمة الناتجة عندما يكون عدم التناظر النسبي للفضاء مساوياً لعدم

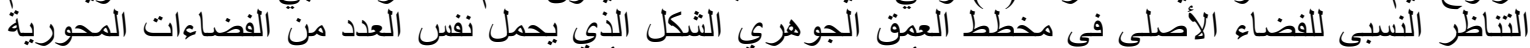

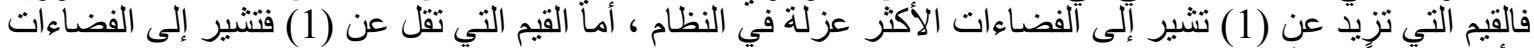
الأكثر تكأملاً في النظام.

2 -2 معدل درجة التكامل للفضاءات التي هي بتماس مع المسجد الجامع :

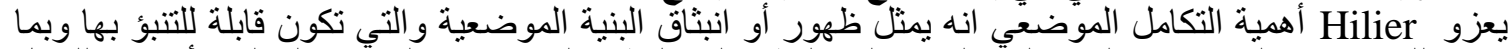

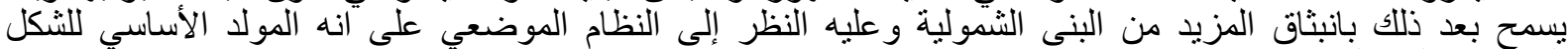
الحضر بعي الشمولي (Hillier,1996)

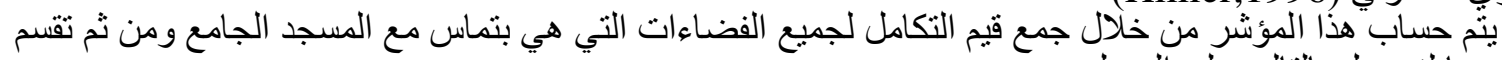

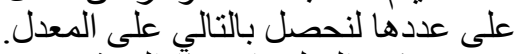

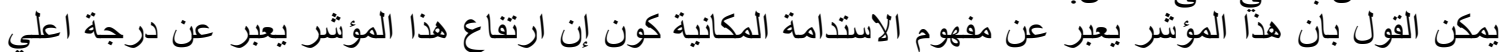

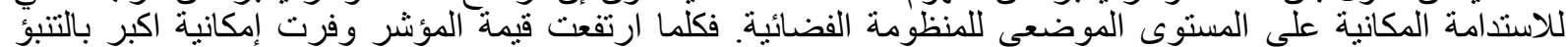

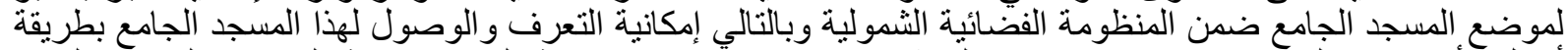

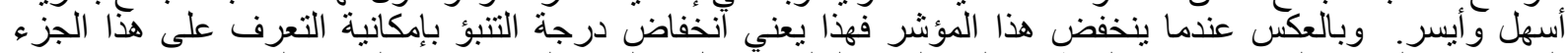

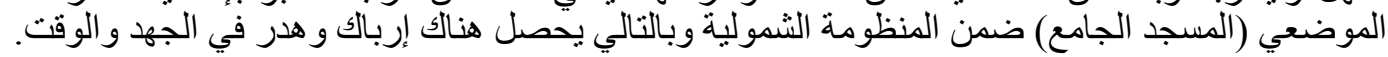

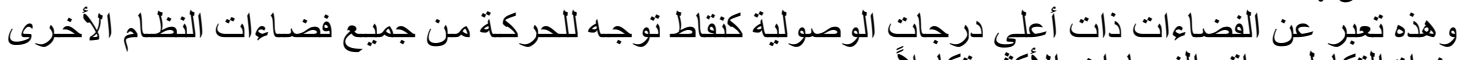

3-3 2

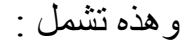

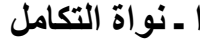

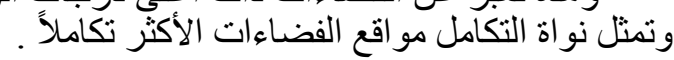

و هذه تعبر عن أعزل أكثر الفضاءات عزلةًَ و اقلها وصوليةً كنقاط نوجه للحركة من جميع فضاءات النظام الأخرى وتمثل نواة العزل مو اقع الفضاءات الأقل تكاملاً.

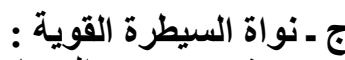

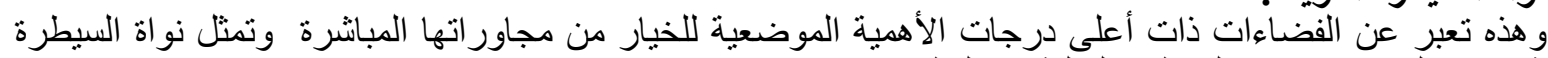
القوية مو اقع الفضاءعات ذات السيطرة العالية في النظام.

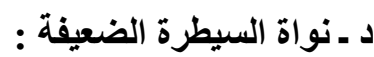
و هذه تعبر عن الفضّاءات ذات أوات أوطأ درجات الأهمية الموضعية للخيار من مجاور اتها المباشرة وتمثل نواة السيطرة الضعيفة مو اقع الفضاءات ذات السيطرة المنخفضة في النظام.

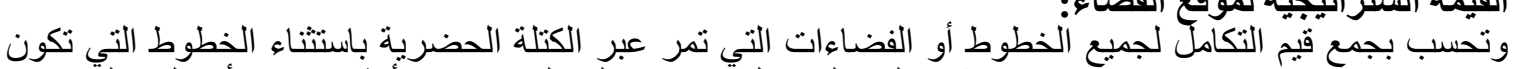
بتماس مع حافاتها ( Karimi, 1997 (1).حيث تثير القيم التي تقل عن (1) إلى الفضاءاء الأكثر تكاملا. أما القيم التي تزيد عن (1) إلى الفضاءات الأكثر عزلة.

ثنالثاً ـ قياس خصائص بنية النظام الفضائي و وهذه تشمل : 1 - نواة السيطرة الثمولية القوية :

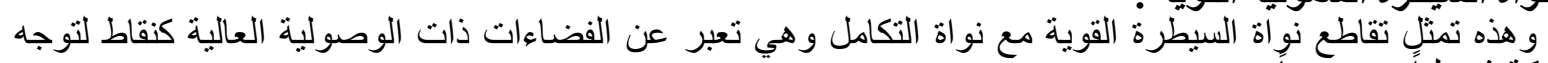

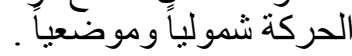

2 ـ نواة السيطرة الشمولية الضعيفة :

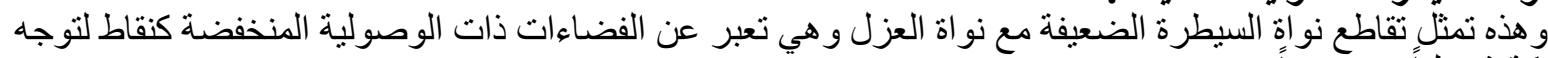
الحركة شمولياً وموضعياً.

3 ـ الوضوحية :

و هذه تمثل الترابط بين قيم التكامل و السيطرة لفضاءات النظام ويتم اعتماد معامل بيرسون للارتباط ( r r م ) كمقياس

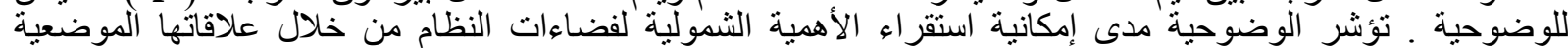
تتزراوح قيم الوضوحية ما بين (1+1)و و(1) . 
رابعاً ـ مؤشر الاستدامة المكانية :

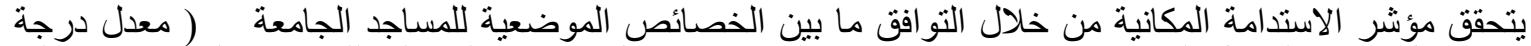

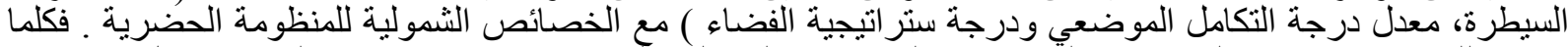
كان هنالك تو افق اكبر بين الخصائص الموضعية و الخصائص الثمولية كلما تحقق مفهوم الاستدامة المكانية بشكل اكبر.

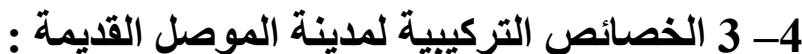

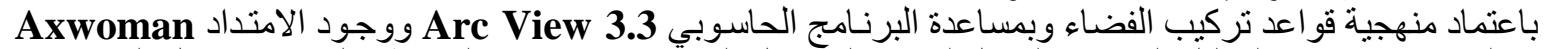

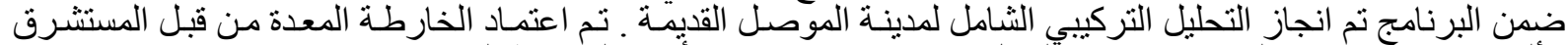

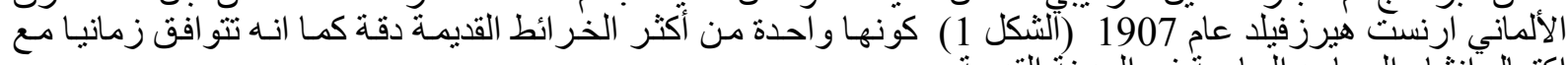
اكتمال إنثاء المساجد الجامعة في المدينة القديمة.

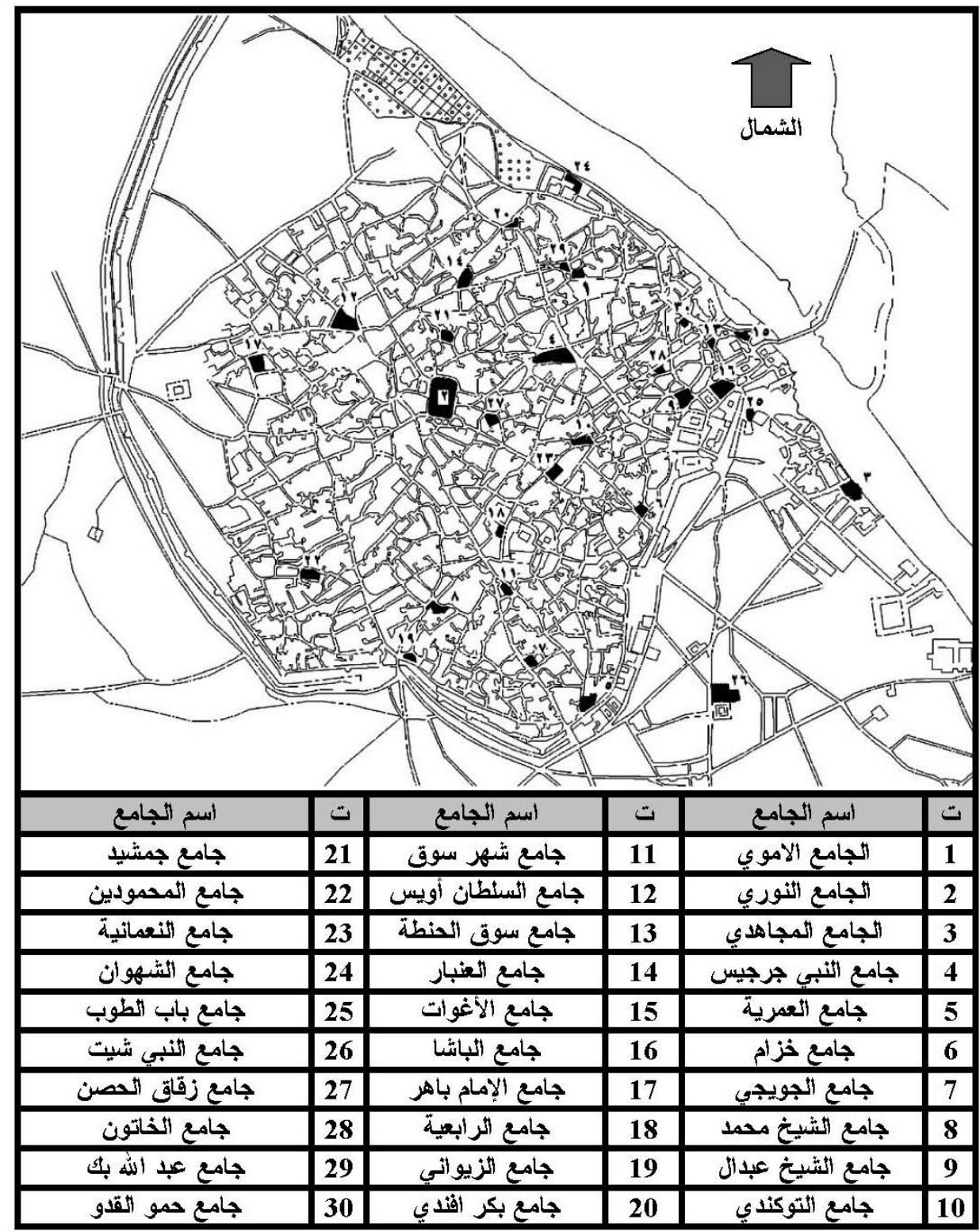

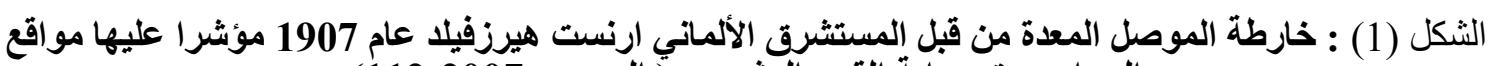

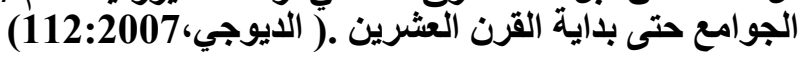

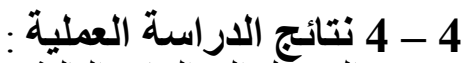
تم التوصل إلى النتائج التالية : 1 - عدد فضاءات النظام بلغ (1053) فضاء النّاء

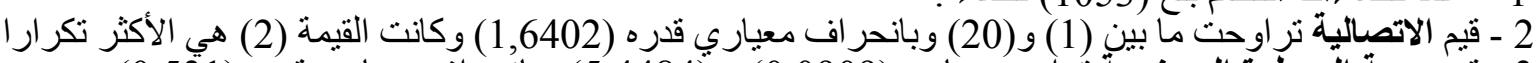

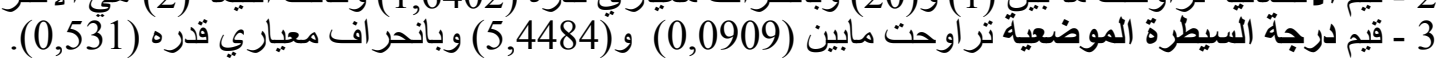


4 - قيم التكامل لفضاءآت النظام تراوحت مابين (0,4896) و (0,1732) (0,9632) وبانحر اف معياري قدره (0,0882)

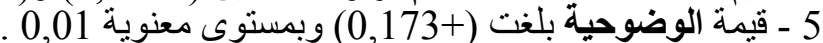

الثكل (2)، و الثكل (3) يوضحان مو اقع الفضاءات الاعلى اتصالية والاقل اتصالية، الثنكل (4 ) و والثكل (5 (5 )

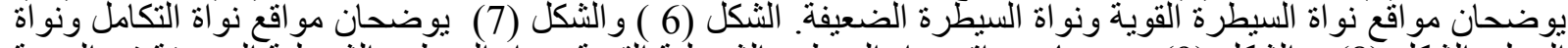
الكزل. الثنكل (8) و الثكل (9) يوضحان مو اقع نواة السيطرة الثمولية القوية ونو الثية اة السيطرة الثمولية الضعيفة في المدينة أي خصائص بنية النظام الفضائي للمدينة.

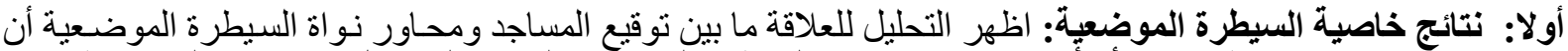

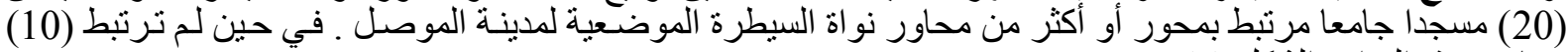

مساجد بهذه النواة ـ الثكل (8) مانط ثانيا: نتائج خاصية التكامل : اظهر التحليل فيما يخص العلاقة ما بين توقيع المساجد الجامعة ونواة التكامل للنظام الفضائي

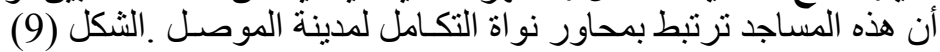

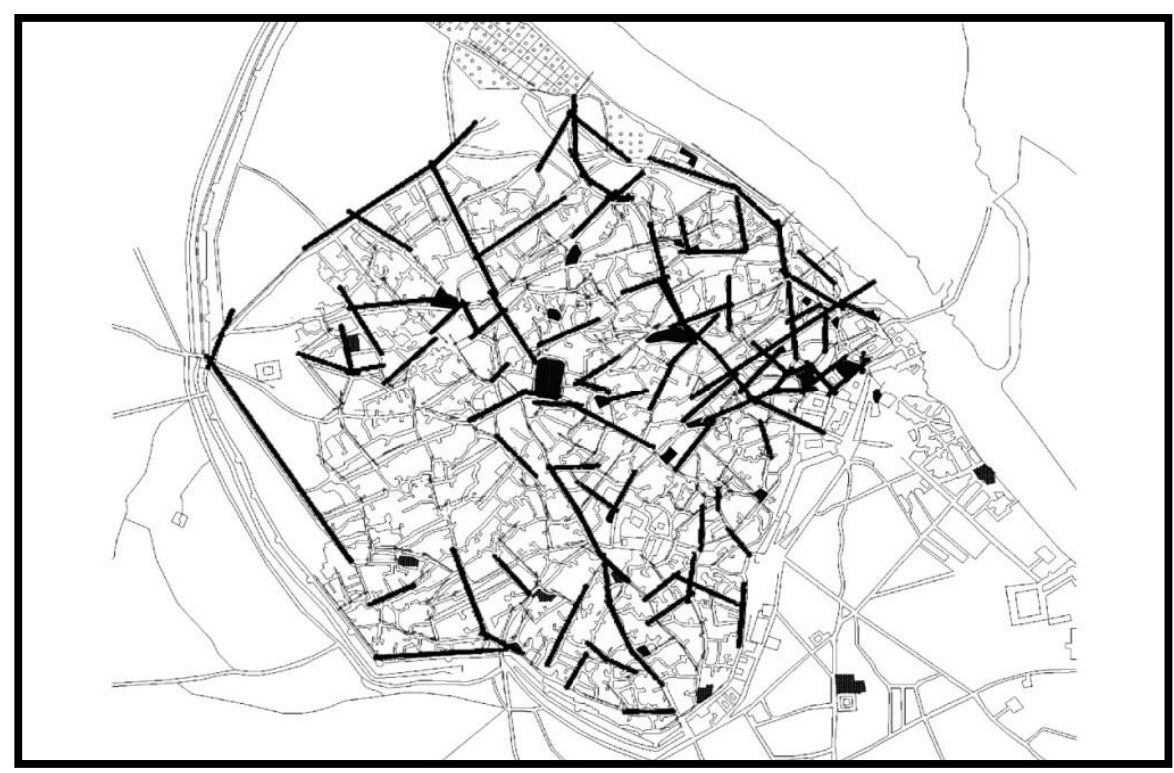

$$
\text { الثٔكل (2) :الفضآت الباحث). }
$$

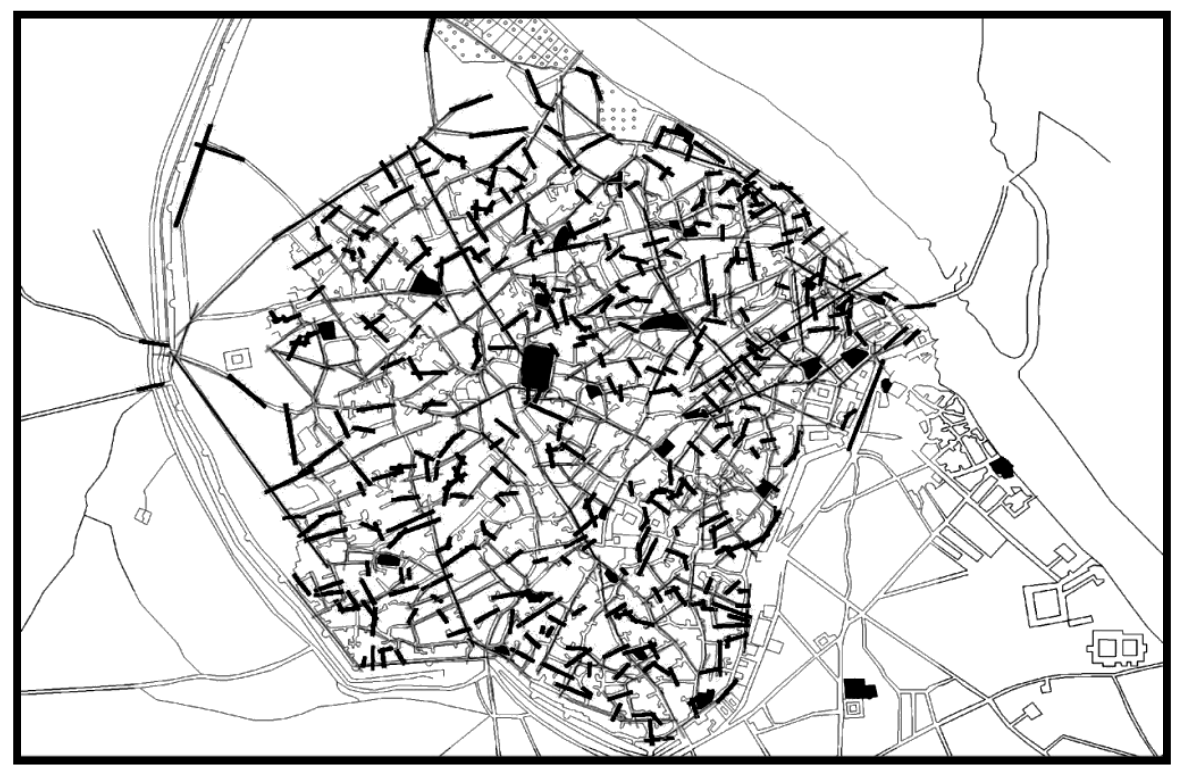

الثكل (3) :الفضآت ألأقل

$$
\text { (الباحثة) }
$$


No. 3

June 2013

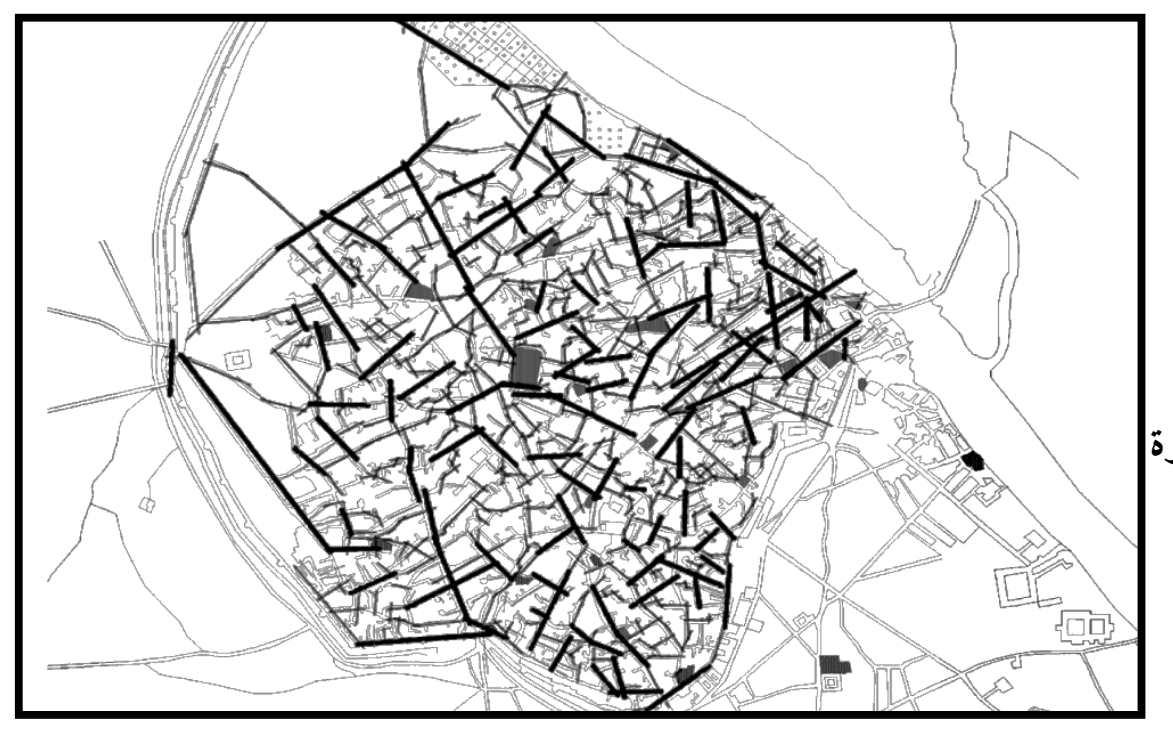

الثكل (4) :نواة السيطرة

القوية ـ (الباحث) :نواثل

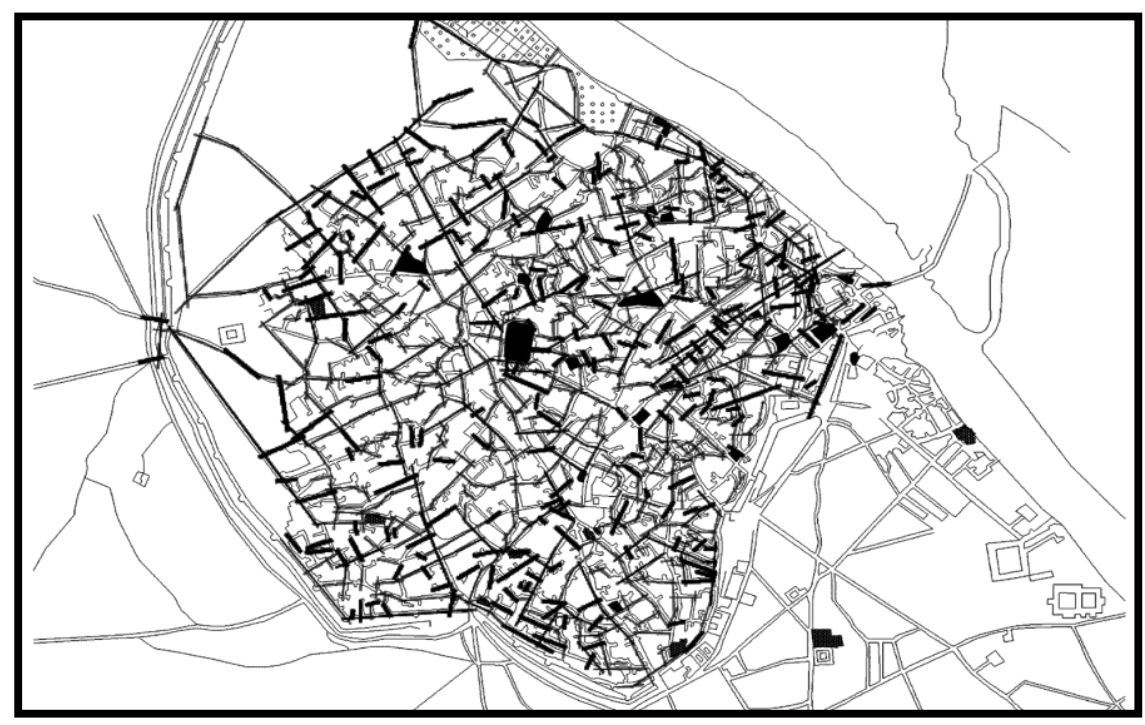

الشكل (5) :نواة السيطرة

الضعيفة ـ (الباحث) :نواة النيطرة

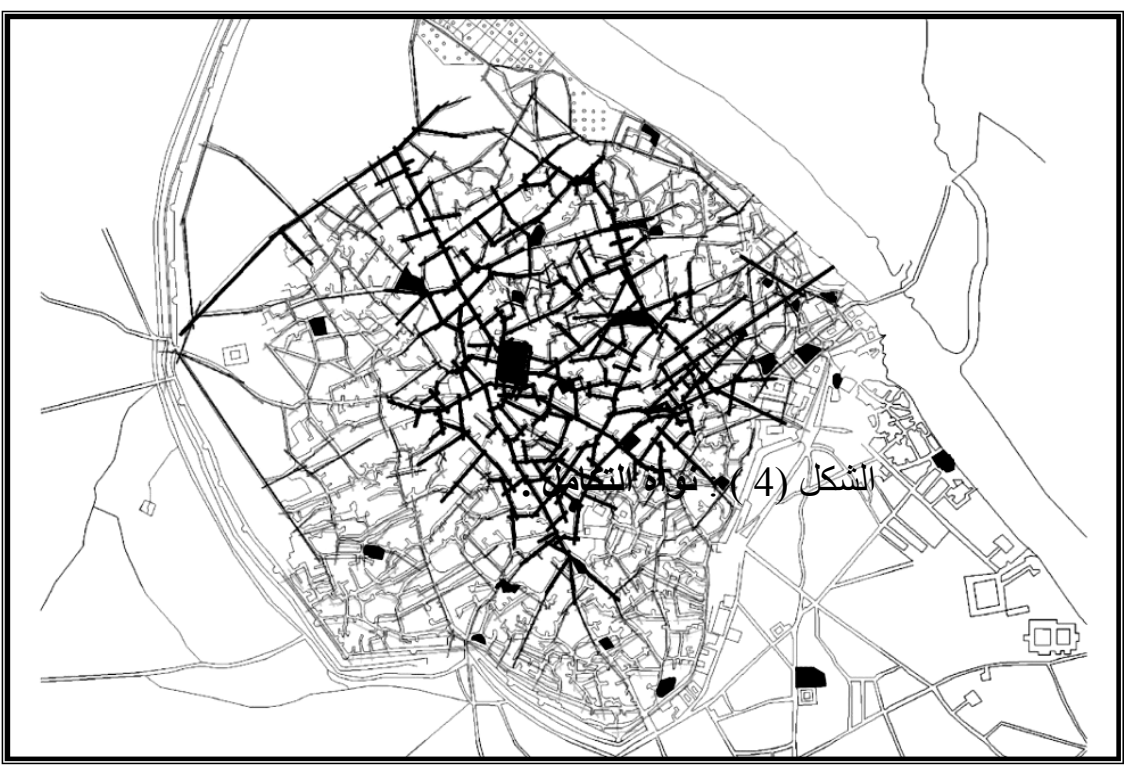

الثكل (6) :نواة التكامل (الباحث) 


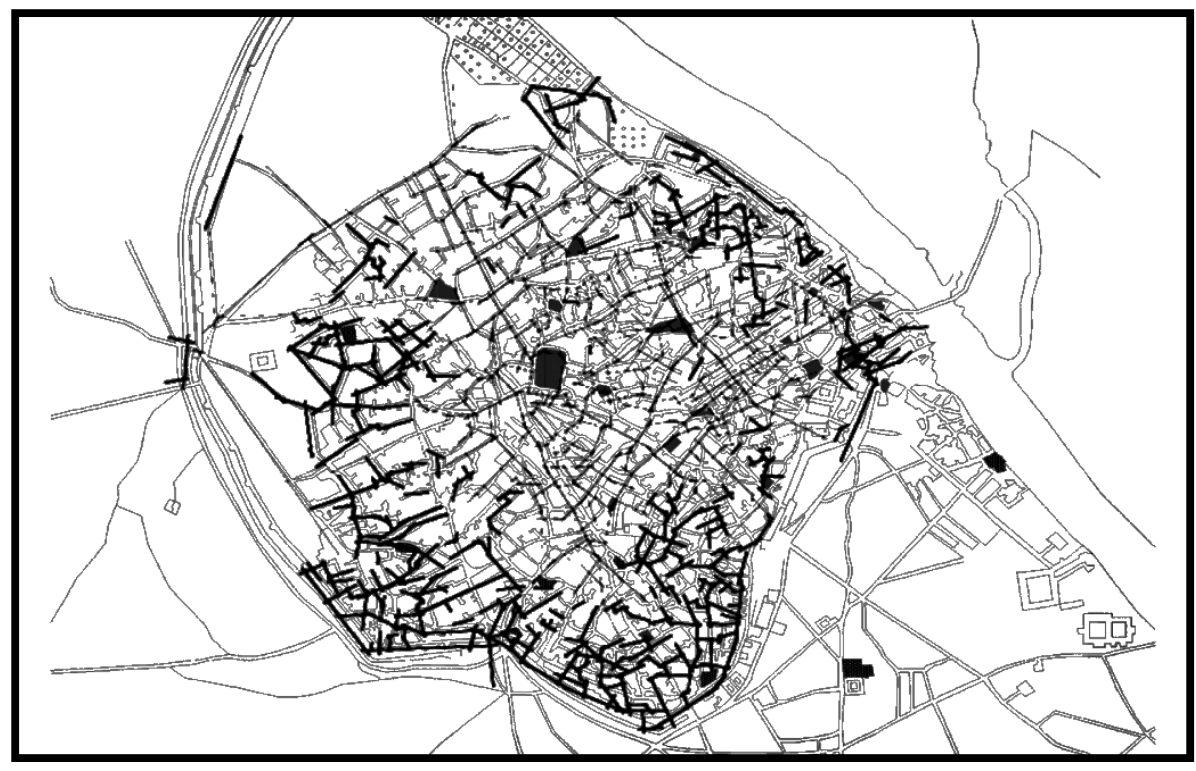

الثكل (7) : النواة العزل (الباحث)

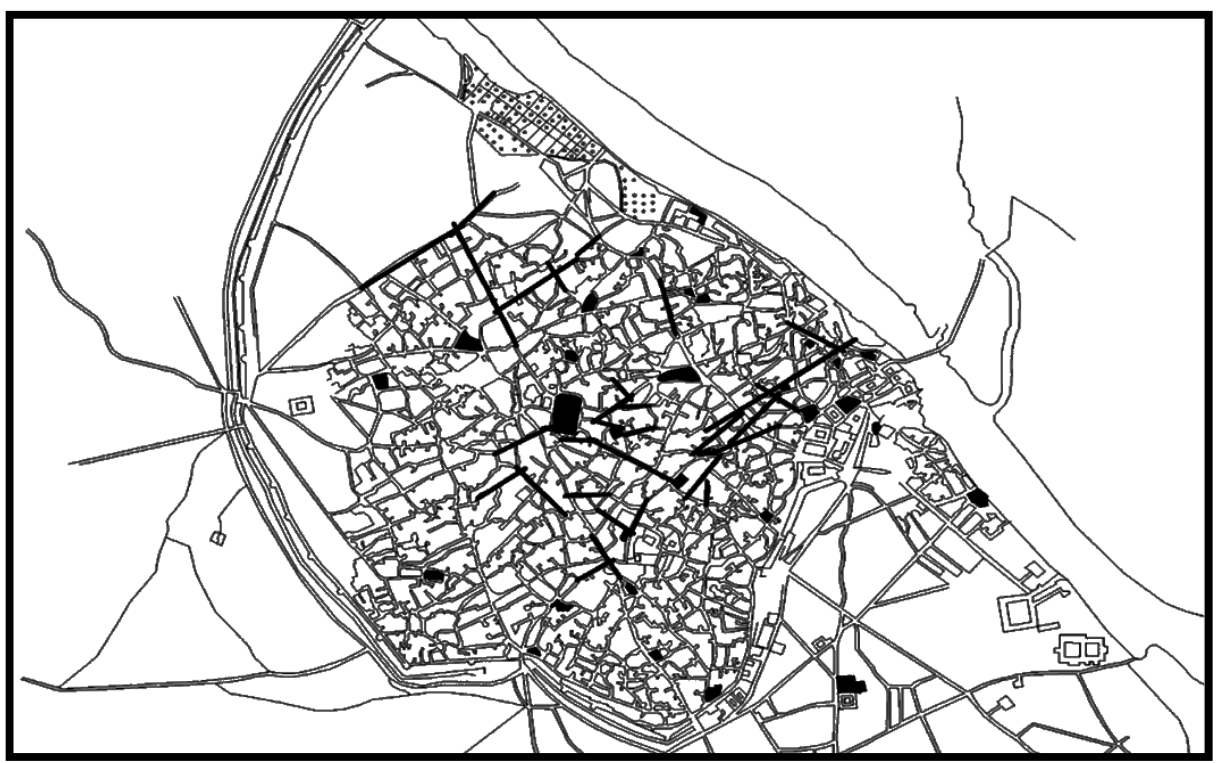

الشكل (8) : النواة السيطرة الثمولية القوية (الباحث)

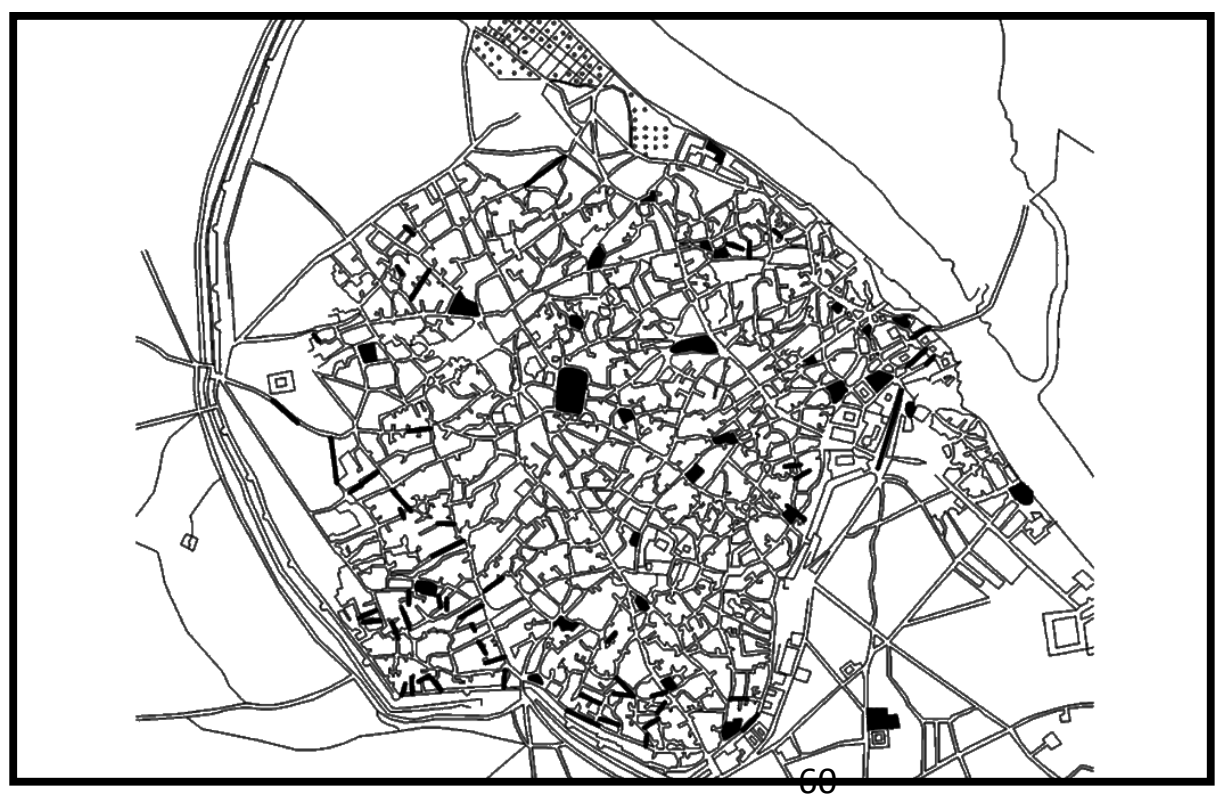

الثكل (9) :نواة السيطرة الثمولية الضعيفة (الباحث) 


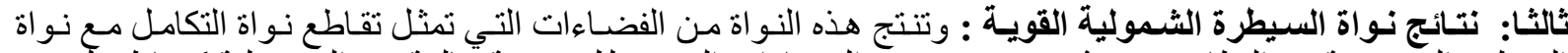

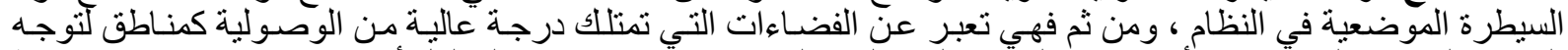

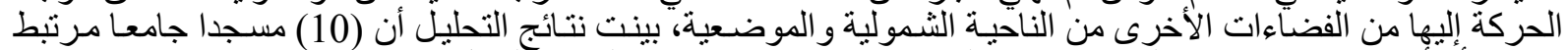

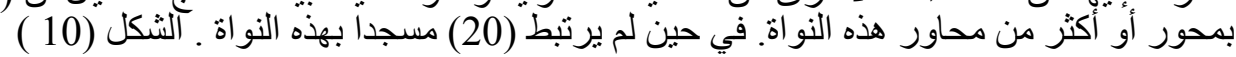

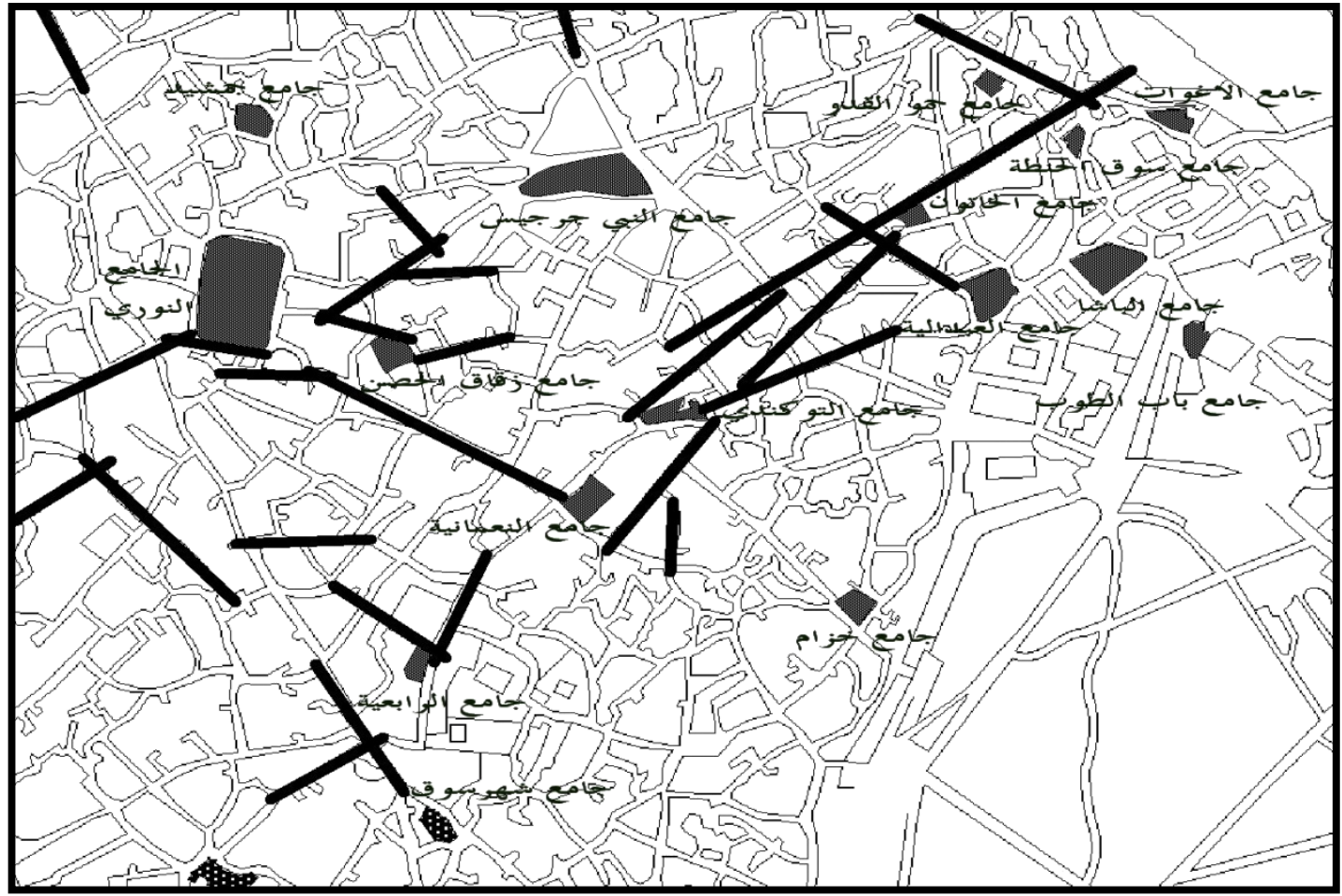

الثكل (10 ) : علاقة مواقع الجوامع مع نواة السيطرة الثمولية القوية ـ (الباحث)

رابعا: نتائج مؤشر ات الخصائص الموضعية:

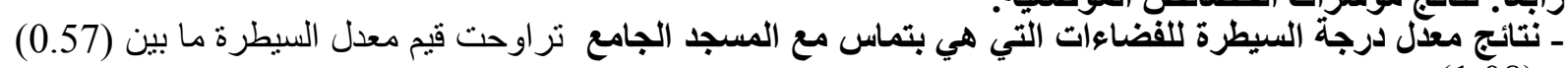

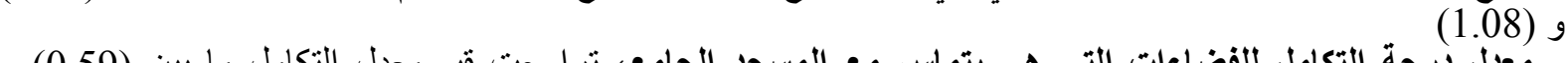
ـ معدل درجة التكامل للفضاءات التي هي بتماس مع المسجد الجامع، تراوحت قيم معدل التكامل ما بين (0.59) و

ـ نتائج القيمة الستراتيجية لموقع المسجد الجامع نراوحت القيمة الستر اتيجية للفضاءات ما بين (0.64) و (0.87)

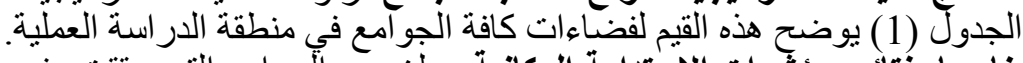

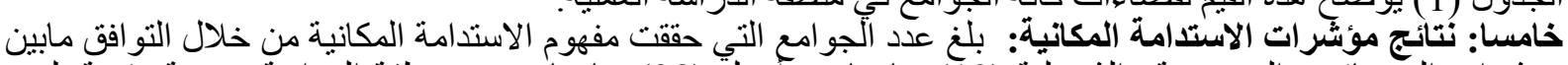

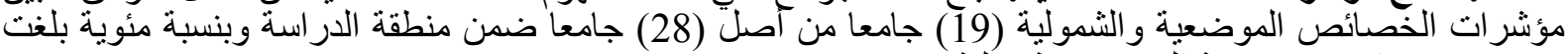
(67.8\%) مما يحقق فرضية البحث بنسبة عالية.

$$
\text { - } 5
$$

أثنتت الأراسة فيما يخص الجانب المتعلق بأسلوب نوقيع المساجد الجامعة المنتشرة ضمن نسيج مدينة الموصل

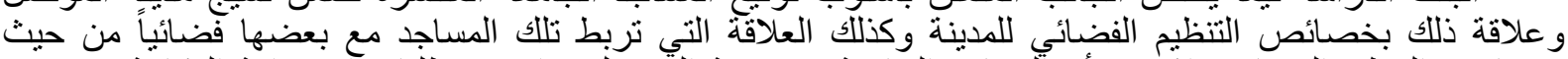

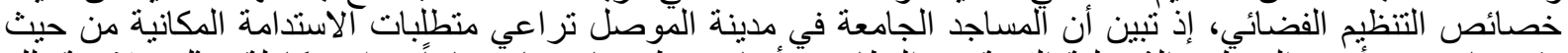

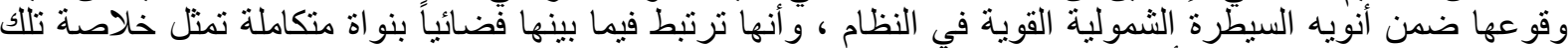

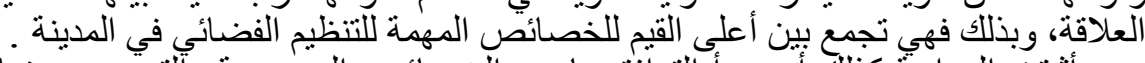

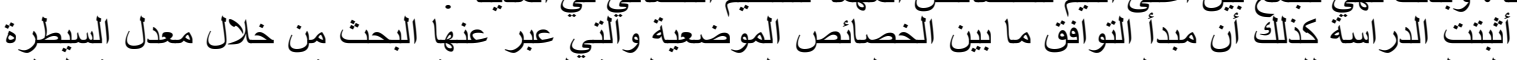

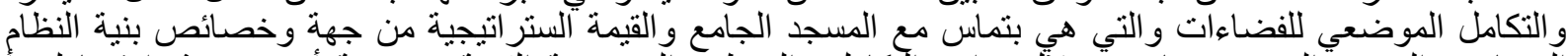

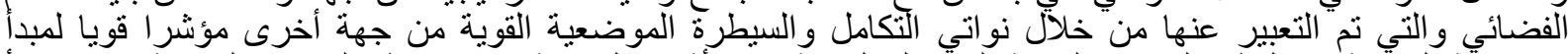
الاستدامة المكانية في النظام الفضائي لمدينة الموصل القديمة حيث أثنتت الدر اسة وقوع معظم المساجد الجامعة ضمن مبدأ 
كذللك أثتتت الدر اسة بان المساجد الجامعة تحتل مو اقع القوة في المنظومة الحضرية وهو ما تمت الإشارة إليه في البحث

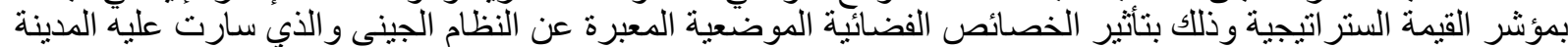

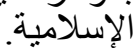

الجدول (1) : قيم مؤشرات الاستدامة المكاتية لفضاءات الجوامع في منطقة الدراسة العملية. (الباحث)

\begin{tabular}{|c|c|c|c|c|c|c|c|}
\hline \multicolumn{2}{|c|}{ مؤشر الاستيّامهة } & \multirow{2}{*}{ 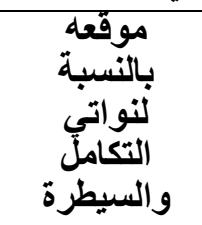 } & \multirow[t]{2}{*}{ الاسترأتيجية } & \multirow[t]{2}{*}{ تكامل } & \multirow[t]{2}{*}{ سيطرة } & \multirow[t]{2}{*}{ اسم الجامع } & \multirow[t]{2}{*}{ ت } \\
\hline لايحقق & يحقق & & & & & & \\
\hline & $\bullet$ & ضمن الانوية & 0.7 & 0.7 & 0.8 & الجامع الاموي & 1 \\
\hline & \multirow[t]{2}{*}{$\bullet$} & ضمن الانوية & 0.87 & 0.86 & 0.98 & الجامع النوري & 2 \\
\hline & & خارج الانوية & \multicolumn{3}{|c|}{ خارج منطقة البحث } & الجامع المجاهدي & 3 \\
\hline & $\bullet$ & ضمن الانوية & 0.792 & 0.8 & 0.86 & جامع النبي & 4 \\
\hline$\bullet$ & & خارج الانوية & 0.565 & 0.56 & 0.935 & جامع العمرية & 5 \\
\hline \multirow[t]{2}{*}{$\bullet$} & & خارج الانوية & 0.74 & 0.65 & 0.982 & جامع خز ام & 6 \\
\hline & • & ضمن الانوية & 0.63 & 0.59 & 0.7 & جامع الجويجي & 7 \\
\hline \multirow[t]{4}{*}{$\bullet$} & & خارج الانوية & 0.676 & 0.65 & 0.66 & جامع الثيخ محمد & 8 \\
\hline & $\bullet$ & ضمن الانوية & 0.716 & 0.66 & 1.08 & جامع الثيخ عبدال & 9 \\
\hline & $\bullet$ & ضمن الانوية & 0.81 & 0.86 & 1.03 & جامع التوكندي & 10 \\
\hline & $\bullet$ & ضمن الانوية & 0.68 & 0.81 & 0.963 & جامع شهر سوق & 11 \\
\hline \multirow[t]{5}{*}{$\bullet$} & & خارج الانوية & 0.73 & 0.73 & 1.06 & جامع السلطان & 12 \\
\hline & $\bullet$ & ضمن الانوية & 0.68 & 0.66 & 1.04 & جامع سوق الحنطة & 13 \\
\hline & $\bullet$ & ضمن الانوية & 0.74 & 0.71 & 0.77 & جامع العنبار & 14 \\
\hline & $\bullet$ & ضمن الانوية & 0.7 & 0.68 & 1.07 & جامع الاغوات & 15 \\
\hline & $\bullet$ & ضمن الانوية & 0.62 & 0.65 & 1.15 & جامع الباثـا & 16 \\
\hline \multirow[t]{2}{*}{ • } & & خارج الانوية & 0.63 & 0.59 & 0.7 & جامع الامام باهر & 17 \\
\hline & $\bullet$ & ضمن الانوية & 0.84 & 0.69 & 0.82 & جامع الر ابعية & 18 \\
\hline \multirow[t]{3}{*}{ - } & & خارج الانوية & 0.725 & 0.67 & 0.59 & جامع الزيو اني & 19 \\
\hline & $\bullet$ & ضمن الانوية & 0.69 & 0.69 & 0.75 & جامع بكر افندي & 20 \\
\hline & $\bullet$ & ضمن الانوية & 0.735 & 0.69 & 0.57 & جامع جمشيد & 21 \\
\hline \multirow[t]{2}{*}{$\bullet$} & & خارج الانوية & 0.607 & 0.64 & 1.08 & جامع المحمودين & 22 \\
\hline & $\bullet$ & ضمن الانوية & 0.79 & 0.74 & 1.21 & جامع النعمانية & 23 \\
\hline$\bullet$ & & خارج الانوية & 0.663 & 0.67 & 0.7 & جامع الثهوان & 24 \\
\hline \multirow[t]{6}{*}{$\bullet$} & & خارج الانوية & 0.64 & 0.66 & 0.79 & جامع باب الطوب & 25 \\
\hline & & خارج الانوية & \multicolumn{3}{|c|}{ خارج منطقة البحث } & جامع النبي شيت & 26 \\
\hline & $\bullet$ & ضمن الانوية & 0.826 & 0.745 & 0.89 & جامع زقاق الحصن & 27 \\
\hline & $\bullet$ & ضمن الانوية & 0.73 & 0.71 & 0.91 & جامع الخاتون & 28 \\
\hline & $\bullet$ & ضمن الانوية & 0.716 & 0.669 & 1.08 & جامع عبداله بك & 29 \\
\hline & $\bullet$ & ضمن الانوبة & 0.65 & 0.70 & 0.70 & جامع حمو القدو & 30 \\
\hline$\% 32.2$ & $\% 67.8$ & & & بنة المئوي & & & \\
\hline
\end{tabular}


1 المصادر : الاشعبث ، خالص ، المحلة العربية التقليدية بين الأصالة والتحديث ،سلسلة المائدة الحرة ، العدد 14 ،بيت الحكمة ،

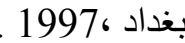

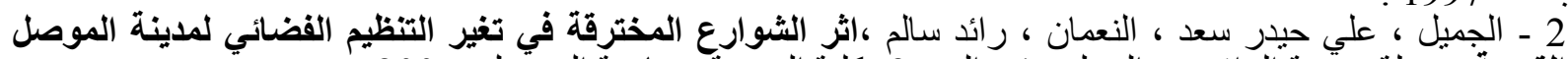

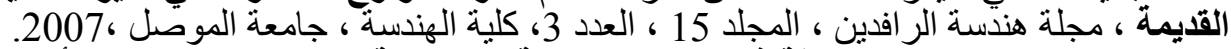

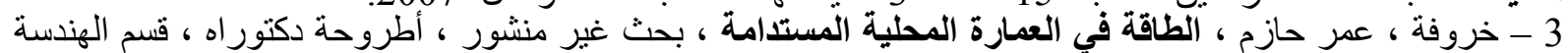

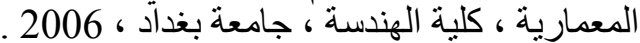

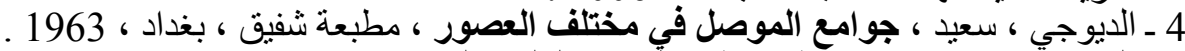

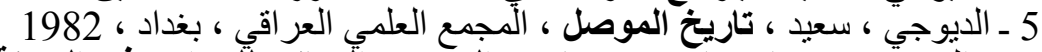

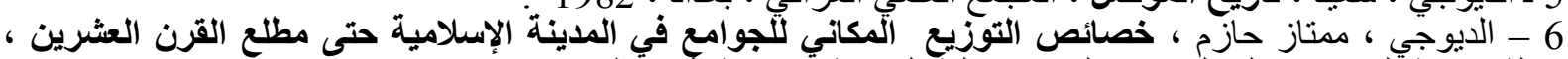

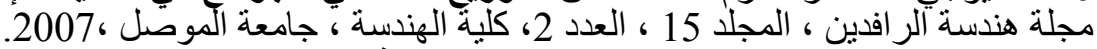

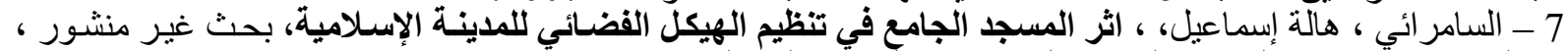

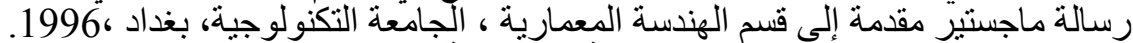

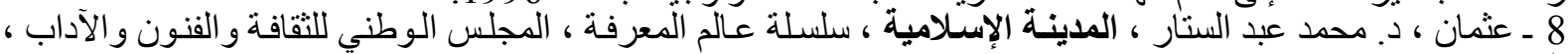
الكويت ، 1988 . 198

9 - الغامدي ، عبد العزيز بن صقر ، الغريت ، دراسة عن مواقع المساجد بمدينة مكة المكرمة ، مطبوعات نادي مكة الثقافي الأدبي ، 1407 هوبية 140

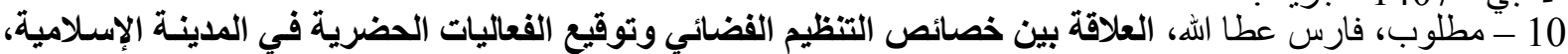

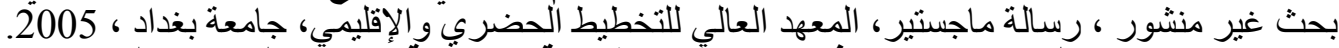

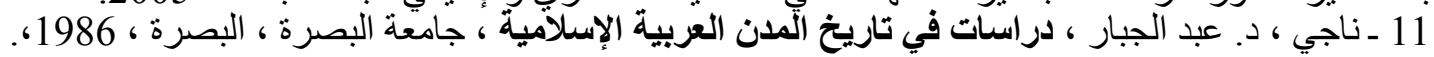

12- Barton, Hugh, Sustainable Urban Design, Urban Design Quarterly, Issue 57, January 1996, Urban Design Group.

13 - Frey ,Hildebrand, Designing the City: Towards a More Sustainable Urban Form, E \& FN Spon.London,1999.

14- Glass ,Jacqueline, Encyclopedia of Architectural Technology ,Wiley-Academy, England,2002

15- Golany ,Gideon ,Design for Arid Regions , Van Nostrand Reinhold Co., New York,1997 16 - Hillier, Bill, And Hanson, Julienne, The Social Logic of Space , Cambridge University Press, Cambridge, 1984 .

17 - Hillier, Bill, Space is the Machine, Cambridge University Press, Cambridge.1996 .

18 - Hillier, Bill, Spatial Sustainability in Cities, Proceedings of the international space syntax symposium, 2009 .,

19 - Jenks ,Mike, Burton ,Elizabeth and Williams, Katie (Eds). The Compact City: A

Sustainable Urban Form?, Spon Press , London , 1996.

20- Miller,G. Tyler, Environmental Science: Working with the Earth , $8^{\text {th }}$. Ed., Thomson Brooks/Cole, Baltimore ,2001.

21- Punter ,John \& Carmona, Matthew , The Design Dimension of Planning: Theory, content and best practice for design policies, E \& FN Spon ,UK,1997 .

22-Rapoport, Amos, House Form and Culture, Printice Hall Inc. 1969.

23- Rosenbaum , Walter, Environmental Politics and Policy, $7^{\text {th }}$.ed.,CQ Press, Washington ,2008..

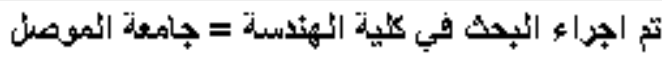

